Canadian

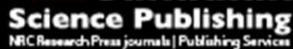

Canadian Geotechnical Journal Revue canadienne de géotechnique

\title{
Determination of the permeability of overconsolidated clay from pressuremeter pressure hold tests
}

\begin{tabular}{|r|l|}
\hline Journal: & Canadian Geotechnical Journal \\
\hline Manuscript ID & cgj-2017-0279.R1 \\
\hline Manuscript Type: & Article \\
\hline Date Submitted by the Author: & 09-Aug-2017 \\
\hline Complete List of Authors: & $\begin{array}{l}\text { Liu, Lang; University of Alberta, Civil and Environmental Engineering } \\
\text { Elwood, David; University of Saskatchewan, Civil and Geological } \\
\text { Engineering } \\
\text { Martin, C. Derek; University of Alberta, } \\
\text { Chalaturnyk, Rick; University of Alberta, Civil \& Environmental Engineering }\end{array}$ \\
\hline Keyword: & $\begin{array}{l}\text { in situ testing, Pressuremeter testing, Pressure hold test, in situ } \\
\text { consolidation, finite element analysis }\end{array}$ \\
\hline &
\end{tabular}

SCHOLARONE ${ }^{m}$

Manuscripts 


\title{
Determination of the permeability of overconsolidated clay from pressuremeter pressure hold tests
}

\section{Lang Liu, David Elwood, Derek Martin, and Rick Chalaturnyk}

\begin{abstract}
A method was developed to interpret the horizontal permeability $\left(k_{h}\right)$ from pressuremeter pressure hold tests (PHT) of approximately $3 \mathrm{~min}$ duration. The method relies on a regression analysis of the numerical analysis simulating the consolidation of clay under a constant pressure boundary during undrained expansion. The method was applied to a series of PHTs performed in deep clay formations in the Seattle area. The interpreted permeabilities are thought to be more representative of in situ conditions than those determined by laboratory testing by virtue of reduced disturbance during sample recovery and preparation. Results could be improved with a further exclusion of the creep effect on PHT.
\end{abstract}

Key words: Pressuremeter, consolidation, overconsolidated clay, permeability, in situ testing, finite element analysis

\section{Introduction}

One of the major challenges with overconsolidated clay is determining representative insitu soil parameters. Due to the high degree of state dependence, sample disturbance, and sample size, consistent and reliable laboratory data are often difficult to obtain (Schmertmann 1955; Lo 1970; Morgenstern and Thomson 1971; Olson and Daniel 1981; Hight et al. 2007). In situ test methods are often used to minimize disturbance and 
maintain in situ stresses as close to the native state as possible (Wroth 1984). Historically, pressuremeters have provided detailed information regarding the shear modulus, horizontal earth pressure coefficient, and drained and undrained shear strength of soil. Consolidation tests using a pressuremeter are typically conducted by holding the maximum strain $(\sim 10 \%)$ constant also known as the Strain Hold Test (SHT) (Clarke et al. 1979). Radial consolidation after expansion of a borehole has been commonly portrayed by the excess pore-water pressure decay measured at the cavity surface. The ability to measure excess pore-water pressure change with a diaphragm type transducer allows determination of the consolidation and/or permeability coefficients by interpreting the excess pore-water pressure dissipation curve (Fahey and Carter 1986; Fioravante et al. 1994; Huang et al. 1990; Jang et al. 2003).

During the SHT test, the excess pore-water pressure decay at a constant borehole strain is monitored to determine the excess pore-water pressure response with time. This requires the operator to continually adjust the pressure to maintain a near constant strain in the pressuremeter probe. This has the same effect as an excess pore-water pressure dissipation test for a piezocone (CPTu) pushed into a cohesive deposit. At high pressures, however, this decay can be rapid and the rate of pressure correction is often difficult to maintain. This test also requires the presence of a pore-water pressure transducer to be located on the surface of the dilatometer and in intimate contact with the surrounding soil at all times. This is not always feasible because not all pressuremeters are equipped with pore-water pressure transducers and the presence of a steel lantern may also prevent porewater pressure measurements. 
This paper discusses the development of a modified analytical method designed to interpret the horizontal permeability and the corresponding coefficient of horizontal volume change from a conventional pressure hold test. This study is not intended to provide a comprehensive solution but rather, is designed to further the discussion and science associated with pore-water pressure decay at the surface of a borehole during a pressure hold test. The steps associated with interpreting strain data when measured in heavily overconsolidated cohesive soils are provided followed by an example of the application of the solution using data from the Greater Seattle area.

\section{Interpretation of Soil Permeabilities from Pressuremeter Pressure Hold Tests (PHT) in Clay}

\section{Consolidation during the PHT}

As with most pressuremeter interpretation methods, polar coordinates and plane strain conditions are assumed for the analysis. This assumes that all strains are in the radial and circumferential directions and that no axial strain is permitted. It is also assumed that the cavity annulus is fully saturated and that excess pore-water pressure only develops within the plastic region, as described by Carter et al. (1979). Because of the low in situ permeability of clay, tests in clay are typically treated as an undrained expansion. However, by maintaining the expansion pressure for a certain amount of time, the excess pore-water pressure would dissipate to the outer field, elastic-plastic boundary. As a result, radial consolidation takes place with the further expansion of the cavity until steady state conditions are reached, as illustrated in Figure 1. It is important to note, that as dissipation of the excess pore-water pressures occur, the effective stress of the ground is increasing and the outer field elastic-plastic boundary is adjusting accordingly. This 
response is similar to that of a constant strain rate consolidation test (Crawford 1965; Vaid et al. 1979; Leroueil 1988). The constant area ratio defined as $\Delta A / A$ and is given as the change in area / the current area per unit length or in terms of circumferential strain, $\varepsilon_{\mathrm{c}}$. Mathematically, this is expressed in Eq. (1).

$\Delta A / A=1-1 /\left(1+\varepsilon_{c}\right)^{2}$

The governing equation of the radial consolidation is given as a function of excess porewater pressure (Randolph and Wroth 1979),

$\frac{\partial u}{\partial t}=c_{h} \frac{\partial^{2} u}{\partial r^{2}}$

where $c_{h}$ is the coefficient of consolidation in the testing plane (horizontal).

As a closed-form solution for pressure-hold test consolidation does not exist, the finite element code Abaqus (Abaqus 2014) is used to simulate the transient response of soils with a fluid-stress coupled model under fixed boundary loadings. The soil is modelled as a Modified Cam Clay (MCC) material but with perfectly plastic behaviour for undrained expansion following the onset of yielding. Undrained expansion is a necessary and sufficient condition in order to accumulate excess pore-water pressures in the near-field soils surrounding a pressuremeter probe. The volume change calculated by the MCC only occurs upon cessation of undrained expansion, corresponding with the start of the pressure hold, consolidation test. Finally, an overconsolidation ratio (OCR) equal to 2 was also assumed. A lower OCR has been assumed in order to maintain the likelihood of saturation of the soils while remaining an overconsolidated soil. In the event that higher OCRs are required, then the method of determining the point of saturation for unsaturated soils during a pressuremeter test (Elwood et al. 2015) must be employed. The model is 
meshed with 100 axisymmetric elements and 503 nodes (Figure 2), graded by a factor of $1 / 25$ with the finest discretization occurring nearest to the borehole boundary. The soil mass was generated assuming a distance to the outer boundary that is 40 times the borehole radius to ensure no boundary effects were observed and the ground can be reasonably considered as an infinite elastic-perfectly plastic medium.

Figure 3 illustrates the excess pore-water pressures and deformations calculated by the numerical model at i) the initial stage prior to undrained expansion; ii) immediately prior to the cessation of loading and the start of the PHT; and iii) completion of the PHT and excess pore-water pressure dissipation.

The typical profile of excess pore-water pressure at different stages of consolidation reported by Randolph and Wroth, 1979 as calculated from the numerical analysis is shown in Figure 4. Unlike one-dimensional consolidation, where the dissipation region is fixed, the dissipation boundary in the case of radial consolidation migrates towards the far field boundary. While the migration of pore water leads to a transient increase of excess pore-water pressure within a given annular region, excess pore-water pressure will eventually return to initial values when consolidation is complete. This also leads to a variation in volumetric change $\varepsilon_{v}\left(\varepsilon_{v}=\varepsilon_{\theta}+\varepsilon_{r}\right)$ in the radial direction, as shown in Figure 5. In this example, the void volumes in the initial elastic zone remain the same at the end of consolidation. For these simulations, the modified Cam Clay model assumes that the shear modulus $G$ is constant and Possion's ratio is defined as a function of the mean effective stress and the void ratio.

These simulations were conducted to verify the numerical model by illustrating the assumptions and findings reported by Randolph and Wroth, 1979. Figures 4 and 5 were 
determined based on the output of the numerical simulations and the parameters used in the models are as shown.

A typical loading curve obtained from the Alaskan Way Viaduct replacement tunnel in Seattle, Washington is shown below in Figure 6. The PHT is highlighted and magnified $200 \%$ in Figure 6 to illustrate the raw data obtained from the test. This brief PHT will be analysed to illustrate the coefficient of volume change of the soil as well as the horizontal permeability for the initial state of stress. Note that the test data has been fit using ideal models described by Gibson and Anderson, 1961 and Jeffries, 1988.

Rather than excess pore-water pressure decay at the cavity boundary, the overall compression in the soil medium is more representative of consolidation progress. As the volumetric strain in the region outside the plastic region eventually becomes zero, consolidation is assumed to only occur within the soil annulus where the materials initially yield. Thus, the calculation of the overall consolidation can be expressed as

$\bar{U}_{t}=\frac{\int_{r_{0}}^{r_{p}} \Delta \varepsilon_{v}}{\int_{r_{0}}^{r_{p}} \Delta \varepsilon_{v_{t=\infty}}}=\frac{V_{p, t=0}-V_{p, t}}{V_{p, t=0}-V_{p, t=\infty}}=\frac{\left(r_{p, t=0}{ }^{2}-r_{0, t=0}{ }^{2}\right)-\left(r_{p, t}{ }^{2}-r_{0, t}{ }^{2}\right)}{\left(r_{p, t=0}{ }^{2}-r_{0, t=0}{ }^{2}\right)-\left(r_{p, t=\infty}{ }^{2}-r_{0, t=\infty}{ }^{2}\right)}$,

where the subscript $p$ denotes the variables at the elastic-plastic boundary. The radius $r$ at time $t$ is the initial radius $r_{t=0}$ and is then subjected to an additional radial displacement $\Delta r$. Then, the overall consolidation can be written as

$\bar{U}_{t}=\frac{2 r_{0, t=0} \Delta r_{0, t}-2 r_{p, t=0} \Delta r_{p, t}+\Delta r_{0, t}^{2}-\Delta r_{p, t}^{2}}{2 r_{0, t=0} \Delta r_{0, t=\infty}-2 r_{p, t=0} \Delta r_{p, t=\infty}+\Delta r_{p, t=\infty}^{2}-\Delta r_{p, t=\infty}^{2}}$

Dividing both numerator and denominator by the initial cavity radius $r_{0, t=0}^{2}$ and removing the infinitesimal terms, Eqn. (4) becomes 
$\bar{U}_{t}=\frac{\varepsilon_{c, t}-R^{2} \varepsilon_{p, t}}{\varepsilon_{c, t=\infty}-R^{2} \varepsilon_{p, t=\infty}}$

where $R$ is the ratio of the boundary of the plastic region to the initial cavity radius, and $\varepsilon_{c}$ and $\varepsilon_{p}$ are the circumferential strains induced by consolidation at the cavity surface and plastic boundaries, respectively.

Eqn. (5) indicates that the average consolidation percentage of a pressure hold test $\bar{U}_{t}$ can be approximated by the variation of radial displacement measured at the cavity surface if the term $R^{2} \varepsilon_{p}$ is considerably smaller than the cavity strain. Figure 7 shows that the difference between the average consolidation $\bar{U}_{t}$ and the radial consolidation $U_{r}$

represented by the change of cavity strain, i.e., $U_{r}=\frac{\varepsilon_{c, t}}{\varepsilon_{c, t=\infty}}$ is minimal and therefore the assumption is considered as reasonable. Also included in Figure 7, is the comparison of the results with the degree of consolidation $U_{\Delta u}$ at the cavity surface indicated by the excess pore-water pressure decay. While excess pore-water pressure dissipation at the membrane-soil interface is significantly faster than average dissipation across the annulus, expansion of the cavity occurs at a reasonably slow rate during consolidation and presents a more gradual and recognizable initial phase of consolidation.

When the computed effective stress path is plotted as is shown in Figure 8, it can be seen that there is no deviation from the total stress path until the unset of yielding at which time, excess pore-water pressures can develop. This response is as would be expected for the MCC model. Note though, in Figure 8, because of the assumption of perfect plasticity during undrained expansion there is no clear deviation of the effective and total stress paths on the initial yield surface. Once the yield surface has been contacted, excess 
pore-water pressures accumulate until the undrained expansion is ceased. At this time, the excess pore-water pressures are permitted to dissipate and the yield surface begins to grow as the effective stress path converges with the total stress path.

\section{Radial Displacement of the Cavity Surface in the Consolidation}

As shown in Figures 4 and 5, the excess pore-water pressure and volumetric strains within the soil at different radii are non-uniform; consolidation takes place with the soil being compressed in the near-cavity region while the soil is unloaded further away from the borehole. In this case, the consolidation coefficients adopted for these two stress paths should be distinguished accordingly. This is because, a single consolidation coefficient used to predict the coupled effect of excess pore-water pressure dissipation and radial displacement would lead to erroneous results (Fioravante et al. 1994; Goh and Fahey 1996).

The consolidation coefficient for excess pore-water pressure dissipation in the horizontal plane is given by Equation (6)

$c_{h}=\frac{k_{h}}{\gamma_{w} m_{h}}$,

where $\gamma_{w}$ is the unit weight of the pore fluid, $k_{h}$ is the in situ horizontal permeability (for a small-strain, pressuremeter test in a low permeability medium, it is assumed that $k_{h}$ is a constant throughout the expansion); and $m_{h}$ is the volumetric compressibility of the soil, which varies spatially and temporally with the current state of the soil skeleton (Randolph et al. 1979). In terms of Cam-Clay parameters, the elastic and plastic definitions can be calculated using Equation (7). 


$$
\begin{aligned}
& m_{h}^{p}=\frac{\lambda}{(1+e) \sigma_{r}^{\prime}} \\
& m_{h}^{e}=\frac{\kappa}{(1+e) \sigma_{r}^{\prime}}
\end{aligned}
$$

where $\lambda$ and $\kappa$ are the volumetric compression indices for the plastic and elastic deformations of soil, respectively. These two parameters are related by the plastic volumetric strain ratio, $\Lambda$, defined as $1-\kappa / \lambda$. Alternatively, $\Lambda$ can also be estimated as $1-C_{r} / C_{c}$ where $C_{r}$ and $C_{c}$ are the slopes of the compression under vertical loadings in odeometer tests. Mayne (1980) published a range of $\Lambda$ for clay based on 105 tests. Mayne indicated that regardless of the clay composition, there was an upper bound around 0.9 and a lower bound around 0.2 for $\Lambda$. Accordingly, the ratio of $\lambda$ to $\kappa$ ranges from 1.25 to 10 for most soils.

Despite the excess pore-water pressure dissipation further hardening the soil in the initial plastic region, the distance to the elastic-plastic boundary undergoes negligible change after the consolidation. The soil is therefore assumed to continue to yield in the initial yield zone $\left(r / r_{0}<R\right)$ while it unloads and reloads elastically in the initial elastic region $\left(r / r_{0}>R\right)$. Thus, for a cavity having the same plastic boundary ratio, $R$ after expansion, the subsequent consolidation can be decomposed into two domains governed by the first and second expressions in Eqn. (7), respectively. $R$ can be expressed as a function of excess pore-water pressure at the cavity surface $\Delta u_{\max }$ and undrained shear strength $s_{u}$ for an elastic perfectly plastic soil (Gibson and Anderson 1961),

$$
R=\exp \left(\Delta u_{\max } / s_{u}\right)
$$


Randolph and Wroth (1979) suggested that the dimensionless form of time $T$ should be used to present the consolidation for a particular ratio of $G / s_{u}$, or $\Delta u_{\max } / s_{u}$ in the case of finite cavity expansion. The time factor is only given when the elastic volumetric compressibility $m_{h}^{e}$ is taken into account,

$$
T^{e}=\frac{k t}{m_{h}^{e} \gamma_{w} r_{0}^{2}}=\frac{k(1+e) \sigma_{r}^{\prime} t}{\kappa \gamma_{w} r_{0}^{2}}
$$

To evaluate the effect of plastic deformation within the yielded region on the radial displacement of the cavity surface during consolidation, PHT on three types of soil with different geo-mechanical properties (Table 1) were simulated with a varying critical state pore pressure parameter, $\Lambda$ (Mayne and Swanson 1981).

Replacing $m_{h}$ with the elastic term $m_{h}^{e}$ and assuming that $e$ is equal to the initial void ratio $e_{o}$ and $\sigma_{r}{ }_{r}$ is equal to the effective radial stress at yielding (i.e., $\sigma_{r}{ }_{r}=\sigma^{\prime}{ }_{0}+s_{u}$ ) in Eqn. 8, the effect of $\Lambda$ can be isolated as shown in Figures 9 and 10, in which the natural logarithm and square root of time factor $T$ are used respectively. Figure 10 is an extension of a consolidation curve to the case of purely elastic deformation $(\Lambda=0)$ from the work of Randolph and Wroth (1979).

Regardless of the absolute magnitude of the consolidation coefficient, the deformation of soil in each domain (plastic or elastic) is proportional to its corresponding compressibility. The integrated radial displacement at the cavity surface has the same fashion of variation for a constant ratio of $\lambda$ to $\kappa$. Nevertheless, a slight mismatch of the curves is observed for high values of $\Lambda$, primarily because the void ratio is significantly reduced as a result of consolidation in highly porous soil so the time factor $T$ determined with the initial void ratio $e_{0}$ is not as accurate as that for soils with low compressibility $(e . g . \Lambda=0.2)$. 
Interpretation of the consolidation coefficient by Clarke et al. (1979), Huang et al. (1990), and Jang et al. (2003) all use the time at $50 \%$ consolidation, i.e., $t_{50}$, be read from a full excess pore-water pressure dissipation curve. Thus, the test needs to be performed over hours, or even days, for soils with extremely low permeability. This creates challenges for in-situ pressuremeter testing when site access and/or work force is limited.

The consolidation curves in Figure 9 exhibits a sigmoidal function regardless of the soil type and permeability. The maximum derivative of each of the curves also occurs at nearly identical points regardless of the soil properties and corresponds with the point of $U_{50}$ or $t_{50}$. This makes determination of the consolidation percentage possible simply by reading the maximum derivative from an unfinished consolidation curve.

When the same data is plotted with respect to the square root of the dimensionless time factor, $T^{e}$ as shown in Figure 10, it would appear that the maximum derivative occurs between 15 to $20 \%$ of $U_{\max }$ regardless of the material characteristics. This observation makes the interpretation more practical since, as will be discussed later, most clays will consolidate to $20 \%$ after several minutes in a hold test.

\section{Interpretation of Permeability Based on the Root Time Consolidation Curve}

As demonstrated by Carter et al. (1979), radial consolidation is also affected by in situ soil parameters, including the permeability $k$, rigidity index $I_{r}$, and maximum excess pore-water pressure $\Delta u_{\max }$ generated at the end of an expansion.

A further study was performed to evaluate the sensitivity of the maximum rate of the degree of consolidation, $(d U)_{\max }$ to these factors with the numerical model. The value of $(d U)_{\max }$ was found to vary over a range between 0.12 and 0.24 with a mean value and standard deviation of 0.17 and 0.022 , respectively (Figure 11). 
The parameters used in the sensitivity analysis are shown below in Table 2. These values were obtained from data provided for the detailed site investigations for the Alaskan Way Viaduct replacement tunnel in Seattle, Washington. This project and the subsequent interpretation of parameters is described later sections.

Note that $s_{u}$ is determined using the formula $s_{u}=\frac{M \sigma_{0}^{\prime}}{\sqrt{3}}\left(\frac{O C R}{2}\right)^{\Lambda}$ (Cao 2001) with the assumption of an $O C R=2$. Further analysis has indicated that the variance of the undrained shear strength has no effect on the results.

With an acceptable degree of deviation, the average of $17 \%$ consolidation is considered the stage at which the maximum derivative of cavity radial displacement would be found in the root time curve. In the same manner as Clarke and Allan's (1990) 50\% excess porewater pressure decay curve, the time factor $T^{e}$ for $17 \%$ percent consolidation can be plotted against the maximum excess pore-water pressure normalized by undrained shear strength (Figure 12). Instead of the single curve for elastic consolidation, however, multiple curves are constructed for various plastic volumetric strain ratios by fitting the numerical results for three types of soils with the exponential or power function

$$
\begin{aligned}
\Delta u_{\max } / S_{u} & =a \cdot \exp \left(b \cdot \ln T^{e}\right), \\
\text { or } \Delta u_{\max } / S_{u} & =a \cdot\left(T^{e}\right)^{b},
\end{aligned}
$$

where $a$ and $b$ are constants for a particular volumetric strain ratio $\Lambda$. The solution, which considers only elastic deformation (i.e., $\Lambda=0$, not shown in Figure 10) would result in a low time factor and therefore underestimate the permeability as well as the coefficient of consolidation. 
Note that the curve fitting parameters have no physical meaning and are based solely on power law curve fitting to numerically simulated data as shown in Figure 12. Figure 12 provides a series of curves fit to the numerical data for a series of soil stiffnesses. These $a$ and $b$ parameters were then plotted with respect to the critical state pore pressure parameter, $\Lambda$ in order to provide a means of estimating the dimensionless time factor $T^{e}$ for any given $\Lambda$ using Equations (11) and (12) below. These data are shown below in Figure 13.

The ratio of $\Delta u_{\max } / s_{u}$ in Figure 11 can be calculated under the assumption of undrained expansion (Gibson and Anderson 1961),

$$
\Delta u_{\max } / s_{u}=\ln \left(\frac{G}{s_{u}} \cdot \frac{\Delta A}{A}\right),
$$

where $G$ and $s_{u}$ can be independently interpreted from the pressuremeter testing curves and the probe volumetric expansion ratio per unit length, $\Delta A / A$ is given above as Equation 1.

Thus, rewriting Eqn. (11) with the time factor given in Eqn. (9), permeability $k$ can be expressed as

$$
k=\frac{m_{h}^{e} \gamma_{w} r_{0}^{2}}{t_{17}}\left(\frac{\Delta u_{\max }}{a s_{u}}\right)^{1 / b}
$$

where, coefficients $a$ and $b$ need to be determined for a particular kind of soil by oedometer testing and the elastic volumetric compressibility $m_{h}^{e}$ can alternatively be estimated from the constrained modulus $M$,

$$
m_{h}^{e}=1 / \mathrm{M}=\frac{1-2 v}{2 G(1-v)}
$$


The other parameters in Eqn. (12) can be interpreted from a full cycle of a pressuremeter test. Figure 14 shows the hold time required for $17 \%$ consolidation in soils of different stiffness. The peak of derivatives in the root time consolidation curve can be reached in under three minutes in a hold test in most clayey materials with permeabilities varying from $\sim 10^{-10}$ to $10^{-7} \mathrm{~cm} / \mathrm{s}$, while in a high permeable medium $\left(>10^{-6} \mathrm{~cm} / \mathrm{s}\right)$ the initial consolidation can barely be captured in the log of radial displacement because pore water quickly dissipates at the start of the hold test.

\section{Pressuremeter Hold Tests in Seattle Clay Deposits}

In order to demonstrate the application of the proposed method of analysis, the analytical method described above was used on data obtained from the ground investigation associated with the design of the Alaskan Way Viaduct replacement tunnel. This tunnel extends beneath downtown Seattle. During this ground investigation, pre-bored pressuremeter tests were carried out in 17 boreholes to measure soil properties including the shear modulus, drained and undrained strength, as well as the horizontal earth pressure at rest. The tests were performed in a variety of deposits including a dense glacial till; stiff glacio-lacustrine and lacustrine clays and silts; as well as a glacial outwash sand and gravel. Pre-bored pressuremeter tests were employed in the most of boreholes. While PHT were performed in both granular and clayey materials, only the stiff clay deposits are interpreted in this study because the range of the cohesive soil permeabilities is within the interpretable range shown in Figure 13.

Other than the well-studied Lawton Clay deposits, the lacustrine and glacio-lacustrine clays in the Pre-Vashon Glacier unit have been well investigated in the Seattle area (Troost and Booth 2008). Having been overridden by at least two glaciations, the clays in 
this deposit are expected to have a highly variable stress history and a wider variation of in-situ conditions (Troost and Booth 2008).

\section{One Dimensional Consolidation Test on Clay Samples}

The consolidation characteristics of the two clay deposits within the proposed tunnel alignment were evaluated by oedometric testing on relatively undisturbed soil samples recovered using a standard Pitcher sampler. Soil properties including the coefficient of consolidation, $c_{v}$ and volumetric compressibility, $m_{v}$ were calculated from the test results (Table 3 and Figure 15). The specimens were found to exhibit a significant variation in compressibility during virgin compression and swelling/recompression, possibly as a result of their different overconsolidation ratios (Mesri et al. 1978). However, the plastic volumetric compression ratio, $\Lambda$ is less dependent on the stress history and was found to be fairly consistent for all of the clay samples examined as part of this study. With a variety of laboratory findings, Mayne and Swanson (1981) also demonstrated that $\Lambda$ is insensitive to in-situ stress anisotropy.

Table 3 suggests, that as expected, the $\Lambda$ parameter is consistent throughout the various boreholes and depths of recovery with an average of 0.812 and a standard deviation of 0.013 . A constant value of $\Lambda$ equal to 0.815 has been selected for the Seattle clay in this study. This then results in time factor, $T^{e}$ constants, $a=2.60$ and $b=0.39$ for Eqn. (10).

\section{Interpretation of Pressuremeter Test Curves}

A slightly undersized pocket was drilled for each of the pressuremeter test holes using a $74.6 \mathrm{~mm}$ diameter tricone bit. The instrument was then advanced into the test pockets as far as possible without causing damage to the instrument. After the pressuremeter was secured in place, the test was performed by injecting compressed nitrogen until a 
maximum cavity strain of around $10 \%$ was achieved. The first PHT was conducted after a cavity strain of approximately 1 to $2 \%$. The cavity strain was calculated with the average value of radial displacements monitored for three axes using $\varepsilon_{c}=\Delta r / r_{0}$. Immediately following the PHT, the borehole pressure was reduced and an unload-reload loop was completed to evaluate the shear modulus of the soils. The borehole expansion was conducted at a normal rate around $5 \mathrm{kPa} / \mathrm{s}$ so that undrained conditions could be assumed for the loading phase.

In order to obtain the variables needed to evaluate Eqn. (12), the pressuremeter test curves were interpreted by focusing on the identification of the undrained shear strength, $s_{u}$ and the shear modulus, $G$. Another important aspect to recognize was the initial disturbance (overcutting or undercutting), because it is important to understand the true cavity strain for the excess pore-water pressure calculation. The presence of disturbance usually results in a shifting of the stress-strain curve.

Noting the concerns above, an interpretation strategy to determine the degree of disturbance for any one test was developed based on the method proposed by Jefferies (1988). An independent analysis of the contraction curve yields a reliable value of undrained shear strength, which is minimally affected by the initial disturbance. The shear modulus was derived from the unload-reload cycles. The contraction curve was reproduced after $s_{u}$ and $G$ were determined and, by assuming that $s_{u}$ is not significantly mobilized in the loading phase, the expansion curve was also plotted using the Gibson and Anderson (1961) undrained cavity expansion model. Finally, the initial disturbance was identified by reconstructing the entire test curve and the field data shifted accordingly. 
As the pocket is smaller than the instrument body, the pressuremeters were pushed in with a certain amount of axial force and the resultant lateral deformation of soil led to a higher lift-off pressure than expected, as shown in Figure 16. Two pressure hold tests were attempted after material yields, as indicated from the pressuremeter expansion curve (e.g., Figure 16). However, in most cases, drilling introduced a certain degree of disturbance to the surrounding soils. Most clays were weak and the borehole surface was severely smeared by the drilling fluid (e.g., Figure 17), resulting in boreholes that were actually oversized for the pressuremeter.

Figures 16 and 17 indicate the field data stress-strain curves as well as the ideal interpretation for both the cavity expansion and contraction. A non-linear regression was conducted to fit the field and idealized expansion and contraction curves and a coefficient of determination was determined. The ideal curves appear to fit the field data well with a minimum $\mathrm{R}^{2}=0.83$. It is important to note, that most errors occur during the initial expansion and immediately before and after an unload-reload loop. Difficulties matching the initial elastic portion with model curves were also encountered by Jefferies (1988). Silvestri and Abou-Samra (2008) showed that soil remoulding and initial drilling unloading significantly changes the soil structure in the near-borehole region and linear sections of the initial expansion are not representative of the true stiffness of the virgin soil.

\section{Interpretation of Pressure Hold Tests}

During each pressuremeter test within the clay deposits, two PHTs were carried out after the onset of yielding. The hold tests were maintained for approximately 3 minutes with the radial displacement monitored at a logging rate of 5 seconds per measurement. The 
proposed method to determine the permeability requires the input of time at $17 \%$ consolidation, which corresponds to the point where the maximum cavity strain rate is observed in the root time curve. An example of two sequential pressure hold tests in Seattle clay is shown in Figures 18 and 19.

By differentiating the curve constructed from the discrete data points, the maximum slope of the strain plot was found. The consolidation rate, i.e., the derivative of the curve, is very sensitive to the inevitable scatter in the measurements if consecutive points are used in the calculation. A technique to reduce the noise and smoothen the variation is to fit the plot with a highly representative function, in this case a cubic polynomial function. The peak shown in the best fitting derivative curve is linked to $17 \%$ consolidation.

The permeability for the clay in borehole TB233 is calculated based on Eqn. (12) for both pressure hold tests (Table 4). To determine the ratio of $\Delta u_{\max } / S_{u}$, the pore water pressure dissipated during past hold tests must be subtracted from the value calculated by Eqn. (12). The reduction of $\Delta u_{\max }$ was estimated with the final percent consolidation at the end of the hold test, but care should be taken because the consolidation presented in terms of the cavity strain significantly underestimates the excess pore-water pressure dissipation at the cavity surface. Thus, a higher permeability was usually interpreted as a result of an overestimated $\Delta u_{\max } / S_{u}$ for the pressure hold test conducted after the first cycle. For this reason, only the permeabilities interpreted from the first test are considered for all of the tests in this study.

\section{Interpretation of Results of Pressure Hold Tests in Seattle Clay}

Values of horizontal permeability $k_{h}$ within Seattle clay were determined at six different locations with the $t_{17}$ obtained from the root time consolidation curves (Figure 20), as 
presented in Table 5. While all of the tests were conducted over a small range of depths between 28 to $44 \mathrm{~m}$ below the ground surface), the horizontal permeability, even at the same depth (e.g., TB233 and TB321), is remarkably inconsistent. Hoopes and Hughes (2014) explained that multiple geological processes, including glacial ice loading and shearing, subglacial pore-water drainage, and deposition and erosion of pro-glacial sediments, combined with ancient earth surface activities such as landslides, might be responsible for the spatial variability and discontinuity of deformation zones even in the same deposits. For example, the test in TB233 was performed in a clay tightly locked in by the surrounding glacial tills, which reasonably exhibits a higher strength than other clays resting in a large deposit.

However, the consistency of the interpretation could still be justified by tests that were conducted within relatively close proximity. At depths of approximately $40 \mathrm{~m}$ below the ground surface, the pressure hold tests conducted in neighbouring boreholes (TB221 and TB318) yield nearly the same horizontal permeabilities. The interpreted permeabilities from pressure hold tests in the same borehole (TB318) at depths only $10 \mathrm{~m}$ apart are also comparable.

Figure 21 shows horizontal permeabilities interpreted from PHT compared with the vertical permeabilities of clay samples measured by laboratory tests. The permeameter testing was performed on tube samples using a flexible wall permeameter by Shannon \& Wilson Inc. The sample was consolidated to $\sigma_{v_{0}}^{\prime}$ before conducting a constant head test. Included in Figure 21 are the permeabilities estimated from the oedometer testing also performed by Shannon and Wilson. 
After the overburden was subjected to multiple cycles of compression and unloading during the cycles of glaciation and interglacial periods, anisotropy of the permeability is likely present within the clay deposits. However, Adams et al. (2013) demonstrated experimentally that the reorientation of fine particles $(0.2-0.7 \mu \mathrm{m})$ did not typically occur when subjected to uniaxial compression and subsequent unloading. In these experiments, they demonstrated an anisotropic permeability ratio, $r_{k}$ where $r_{k}=k_{h} / k_{v}$, varies from 1.2 to 1.9 for a vertical effective stress change between 0.4 to $10 \mathrm{MPa}$. Tavenas et al. (1984) also reported anisotropic permeability measurements on various clay samples that $r_{k}$ is generally less than three in natural clays. Thus, the difference between the permeabilities measured by in situ and laboratory methods might not be attributed to the intrinsic permeability anisotropy. Instead, the quality of the test and the limited accuracy of the testing technique itself could at least be partially responsible for the discrepancy in the results.

As shown in Figure 21, the permeabilities determined by permeameter tests are approximately two or three orders of magnitude higher than those determined by PHT and oedometer tests. As only a very limited flow would be observed in the low permeability clay, the compliance of the testing system may contribute to a significant error in the measurement. Leakage in the external fittings, saturation of membrane and porous stone, and preferred flow through the interface between the membrane and sample would all lead to extra flow and thus overestimation of permeability from the calculation (Tavenas et al. 1983). Provided that the sampling and permeameter testing were performed with adequate control, error could also result from the excessive hydraulic gradient and soil volumetric changes due to perturbance from the injection pressure 
(Olson and Daniel 1981). Consolidating the sample to the initial vertical effective stress would also be insufficient to restore the original soil structure. It has been well documented (Schmertmann 1955; Lo 1970; Morgenstern and Thomson 1971; Olson and Daniel 1981) that sampling and preparation of most overconsolidated soils is sufficient to impact the results of most laboratory tests. Additionally, the high horizontal stresses, measured by Hoopes and Hughes (2014), would have more impact on the hydraulic conductivity in the undisturbed state.

In situ permeability may be better represented by mean effective stress, $p^{\prime}$ calculated for the clays where the PHTs were performed (Figure 22). A trend was observed where the permeability decreases exponentially with an increasing mean effective stress, in accordance with the permeability-stress relation suggested by Vaughan (1994).

The evaluation of permeability through the application of Terzaghi's solution to oedometer testing was also considered unreliable because the assumption that $c_{v}$ is a constant through the consolidation does not reflect the actual consolidation characteristics at the point where $c_{v}$ is interpreted. Compared with the true permeabilities measured by a falling head test during each step of consolidation, Tavenas et al. (1983) reported that permeabilities calculated based on $c_{v}$ likely underestimated the actual permeability by as much as a factor of 10 .

While the consolidation parameters would also experience a considerable variation in PHT, up to the $17 \%$ of consolidation where the analysis is performed, the soil might not undergo significant structural alteration when compared to tests conducted at the end of expansion. Thus, in addition to considerably shortening the time required to carry out a 
test, the interpretation would be less affected by assuming a constant $m_{h}^{e}$ and $k$ for the initial period of consolidation.

In addition to excess pore-water pressure dissipation, the creep behavior of clays has also been noted as a reason for the time-dependent expansion of the pressuremeter membrane during hold tests (Fahey 1988; Goh 1994; Hoopes and Hughes 2014). Anderson et al. (1988) validated the creep effect in pressuremeter testing of cohesive soils but did not quantify the creep effect under the same stress conditions for each stage of loading; thus, there is still no direct evidence that creep would dominate the effective stress change on cavity deformation. A calibration study with only creep allowed (i.e., under totally drained conditions) during a pressuremeter hold test would be valuable to decouple the stress-induced deformation from measurement.

\section{Summary and Conclusions}

The consolidation characteristics under constant radial loading on the cavity surface were numerically assessed for varying constitutive parameters for clays. A statistical analysis of model results suggests that the lapse time at a low consolidation percentage $(\sim 17 \%)$ can be extracted from the root time curve of the radial displacement during the pressuremeter pressure hold test. The deformation of the borehole during PHT is governed by the ratio, $R$ of the plastic boundary, $r$ to the initial borehole radius, $r_{0}$ and the plastic volumetric strain ratio of soil $\Lambda$. Their effects on the time obtained for $17 \%$ consolidation were distinguished in the curves characterized by a non-dimensional time factor $T^{e}$. A method was developed to interpret the permeability of clay deposits with a 3min pressure hold test after the near-field soil yields during the initial expansion. 
The proposed technique was applied to data from PHT in a Seattle clay with reasonable results. The oedometeric test results were used to determine $\Lambda$ and the other required inputs were determined from the conventional interpretation of pressuremeter testing data. Care must be taken when estimating excess pore-water pressure $\Delta u_{\max }$ at the cavity surface at the start of consolidation due to its power-law relation with the interpreted permeability. Collins and Yu (1996) predicted the variation of the generated excess porewater pressure as a function of the overconsolidation ratio under the undrained cavity expansion. $\Delta u_{\max }$ will be underestimated by Eqn. (12) in normally consolidated clay and overestimated in heavily consolidated clay. In either case, a correction may need to be adopted for excess pore-water pressure estimation and an independent excess pore-water pressure measurement also used to calibrate the findings herein. However, a more unpredictable volumetric strain path for soils under different consolidation conditions, as discussed by Fioravante et al. (1994), would increase the difficulties of back-analyzing the horizontal permeability from a PHT.

\section{Acknowledgement}

The authors acknowledge the contribution of Shannon \& Wilson, Inc., Seattle, WA for providing the data. Specifically, we greatly appreciate the input from both Mr. Oliver Hoopes at Shannon \& Wilson and Dr. John Hughes of In Situ Engineering. We would also like to extend our thanks to Dr. Curtis Kelln of GeoStudio for his insight and discussion regarding the numerical modelling as well as the analytical solution. 


\section{References}

Abaqus 2014. ABAQUS Documentation, Dassault Systèmes, Providence, RI, USA.

Adams, A.L., Germaine, J.T., Flemings, P.B., and Day-Stirrat, R.J., 2013. Stress induced permeability anisotropy of resedimented Boston Blue Clay. Water Resources Research 49, p. 1-11. doi:10.1002/wrcr.20470

Anderson, W., Pyrah, I., and Haji Ali, F., 1988. Rate effects in pressuremeter tests in clays. Journal of Geotechnical Engineering 113, 1344-1358.

Cao, L. F., Teh, C. I., and Chang, M. F. 2001. Undrained cavity expansion in modified Cam clay. Geotechnique, 51(4), 323-34.

Carter, J., Randolph, M., and Wroth, C. 1979. Stress and excess pore-water pressure changes in clay during and after the expansion of a cylindrical cavity. International Journal for Numerical and Analytical Methods in Geomechanics 3, 305-322.

Clarke, B.G., and Allan, P.G. 1990. Self-boring pressuremeter tests from a gallery at 220 m below ground, in: Pressuremeters - A British Geotechnical Society Symposium. London.

Clarke, B.G., Carter, J.P., Wroth, C.P., and Science, E. 1979. In situ determination of the consolidation characteristics of saturated clays. Design Parameters in Geotechnical Engineering, VII ECSMFE, Brighton, UK, 2, 207-211.

Collins, I., and $\mathrm{Yu}, \mathrm{H}$. 1996. Undrained cavity expansions in critical state soils. International Journal for Numerical and Analytical Methods in Geomechanics 20, $489-516$. 
Crawford, C.B. 1965. The resistance of soil structure to consolidation. Canadian Geotechnical Journal, 2(2), 90-97.

Elwood, D.E., Martin, C.D., Fredlund, D.G., and Ward Wilson, G. 2015. Volumetric Changes and Point of Saturation around a Pressuremeter Probe Used in Unsaturated Soils. Journal of Geotechnical and Geoenvironmental Engineering, 141(11).

Fahey, M. 1988. Self-boring pressuremeter testing in calcareous soil, in: Jewell, R.J., Andrews, D.C. (Eds.), International Conference on Calcareous Sediments. Balkema, Perth, Australia, pp. 165-173.

Fahey, M., and Carter, J.P. 1986. Some effects of rate of loading and drainage on pressuremeter tests in clay. Proc. Specialty Geomech. Symposium: Interpretation of Field Testing For Design Parameters 50-55.

Fioravante, V., Jamiolkowski, M., and Lancellotta, R. 1994. An analysis of pressuremeter holding tests. Geotechnique 227-238.

Gibson, R., and Anderson, W.F. 1961. In situ measurement of soil properties with the pressuremeter. Civil Engineering Public Works Review 56, 615-618.

Goh, A.L. 1994. A Study of Measuring In-situ the Coefficient of Consolidation of Soft Clay Using Cavity Expansion Methods. University of Western Australia.

Goh, A.L., and Fahey, M. 1996. Measuring the coefficient of consolidation in situ using SBP and piezocone dissipation tests, in: 7th Australia New Zealand Conference on Geomechanics. pp. 915-920. 
Hight, D. W., Gasparre, A., Nishimura, S., Minh, N. A., Jardine, R. J., and Coop, M. R. 2007. Characteristics of the London Clay from the Terminal 5 site at Heathrow Airport. Geotechnique. Vol. 57, pp. 3-18.

Hoopes, O., and Hughes, J. 2014. In situ lateral stress measurement in glaciolacustrine Seattle Clay using the pressuremeter. Journal of Geotechnical and Geoenvironmental Engineering 140, 04013054. doi:10.1061/(ASCE)GT.19435606.0001077

Huang, A., Holtz, R., and Chameau, J. 1990. Pressuremeter holding tests in a calibration chamber. Proceedings of the Third Internation Symposium on Pressuremeters, Oxford, UK; pp. 253-262.

Jang, I.S., Chung, C.-K., Kim, M.M., and Cho, S.M. 2003. Numerical assessment on the consolidation characteristics of clays from strain holding, self-boring pressuremeter test. Computers and Geotechnics 30, 121-140. doi:10.1016/S0266$352 X(02) 00031-9$

Jefferies, M. 1988. Determination of horizontal geostatic stress in clay with self-bored pressuremeter. Canadian Geotechnical Journal 26, 760-763. doi:10.1139/t89-093

Leroueil, S. 1988. Tenth Canadian Geotechnical Colloquium: Recent developments in consolidation of natural clays. Canadian Geotechnical Journal, 25(1), 85-107.

Liu, L. 2015. Numerical Study of Reservoir Geomechanical Pressuremeter Testing under Anisotropic In-situ Stresses. University of Alberta.

Lo, K.Y. 1970. The operational strength of fissured clays. Geotechnique 20, 57-74.

Mayne, P.W. 1980. Cam-clay predictions of undrained strength. Journal of Geotechnical Engineering 106, 1219-1242. 
Mayne, P.W., and Swanson, P.G. 1981. The Critical-State Excess pore-water pressure Parameter from Consolidated- Undrained Shear Tests. ASTM Selected Technical Paper (STP)740, ASTM International, West Conshohocken, PA, pp. 410-430.

Mesri, G., Ullrich, C.R., and Choi, Y.K. 1978. The rate of swelling of overconsolidated clays subject to unloading. Geotechnique 28(3), 281-307.

Morgenstern, N.R., and Thomson, S. 1971. Comparative observations on the use of the pitcher sampler in stiff clay, in: Gordon, B., Crawford, C.B. (Eds.), Sampling of Soil and Rock, ASTM ST STP 483. ASTM, Toronto, Canada, pp. 180-191.

Olson, R.E., and Daniel, D.E. 1981. Measurement of the hydraulic conductivity of finegrained soils. ASTM Special Technical Publication, ASTM International, West Conshohocken, PA, pp. 18-64.

Randolph, M., Carter, J., and Wroth, C. 1979. Driven piles in clay-the effects of installation and subsequent consolidation. Geotechnique 29, 361-393.

Randolph, M., and Wroth, C. 1979. An analytical solution for the consolidation around a driven pile. International Journal for Numerical and Analytical Methods in Geomechanics 3, 217-229.

Schmertmann, J.H. 1955. The undisturbed consolidation behavior of clay. In From Research to Practice in Geotechnical Engineering: (pp. 1-33). ASCE.

Silvestri, V., and Abou-Samra, G. 2008. Analysis of instrumented sharp cone and pressuremeter tests in stiff sensitive clay. Canadian Geotechnical Journal 45, 957972. doi:10.1139/T08-028 
Tavenas, F., Jean, P., Leblond, P., and Leroueil, S. 1984. The permeability of natural soft clays. Part II: Permeability characteristics. Canadian Geotechnical Journal 21, 730-731. doi:10.1139/t84-081

Tavenas, F., Leblond, P., Jean, P., and Leroueil, S. 1983. The permeability of natural soft clays. Part I: Methods of laboratory measurement. Canadian Geotechnical Journal 20, 629-644. doi:10.1139/t83-072

Troost, K., and Booth, D. 2008. Geology of Seattle and Seattle area, Washington. Geological Sociesty of America Reviews in Engineering Geology XX, 1-35. doi:10.1130/2008.4020(01)

Vaid, Y. P., Robertson, P. K., and Campanella, R.G. 1979. Strain rate behaviour of SaintJean-Vianney clay. Canadian Geotechnical Journal, 16(1), 34-42.

Vaughan, P.R. 1994. Assumption, prediction and reality in geotechnical engineering. Géotechnique 44, 573-609. doi:10.1680/geot.1994.44.4.573

Wroth, C.P. 1984. The interpretation of in situ soil tests. Géotechnique 34, 449-489. doi:10.1680/geot.1984.34.4.449 
Figure Captions

Figure 1 Soil states in the cavity annulus before and after consolidation with fixed boundary loadings

Figure 2 Geometry of the numerical model for PHT analysis

Figure 3. Calculated excess pore-water pressures and deformations

Figure 4 Variation of excess pore-water pressure in the soil annulus radius during PHT $\left(I r=G / S_{u}=20, k=10^{-7} \mathrm{~cm} / \mathrm{s}\right.$, and $\left.\Delta u_{\max } / S_{u}=1.6\right)$ (modified from Randolph and Wroth 1979)

Figure 5 Typical variation of volumetric strain in the soil annulus radius during PHT (Ir $=20, k=10^{-7} \mathrm{~cm} / \mathrm{s}$, and $\left.\Delta u_{\max } / S_{u}=1.6\right)$ (modified from Randolph and Wroth, 1979)

Figure 6 Fitting the pressuremeter testing data with the model curve (TB233, $44.3 \mathrm{~m}$ )

Figure 7 Representation of consolidation by excess pore-water pressure decay and radial displacement compared to the true average consolidation curve ( $I r=20, k=10^{-7} \mathrm{~cm} / \mathrm{s}$, and $\left.\Delta u_{\max } / S_{u}=1.6\right)$

Figure 8. Effective and total stress paths during undrained expansion and consolidation

Figure 9 Variation of the normalized radial displacement during consolidation with the logarithm of time $\left(\Delta u_{\max } / s_{u}=1.6\right.$ or $\left.R=4.95\right)$

Figure 10 Variation of the normalized radial displacement during consolidation with the square root of time $\left(\Delta u_{\max } / s_{u}=1.6\right.$ or $\left.R=4.95\right)$

Figure 11 The varying values of $(\mathrm{d} U)_{\max }$ in root time consolidation curves for different in situ parameters and induced excess pore-water pressure conditions from the numerical computation

Figure 12 The non-dimensional time factor curve for $17 \%$ consolidation during a PHT

Figure $13 a$ and $b$ parameters based on numerical results for varying $\Lambda$

Figure 14 Time to reach $17 \%$ consolidation for PHT in soils of different stiffness $(\Lambda=$ $0.75)$

Figure 15 Settlement of clay samples at increasing consolidation pressure

Figure 16 Fitting the pressuremeter testing data with the model curve (TB233, $44.3 \mathrm{~m}$ )

Figure 17 Fitting the pressuremeter testing data with the model curve (TB318, $28 \mathrm{~m}$ )

Figure 18 First hold test at $44.3 \mathrm{~m}$ for borehole TB233

Figure 19 Second hold test at $44.3 \mathrm{~m}$ for borehole TB233

Figure 20 Root time curve of cavity strain variation during pressure hold tests in Seattle clay deposits; the point of $17 \%$ consolidation in each test is marked by a star symbol.

Figure 21 Permeability measured by PHT and laboratory testing versus effective vertical stresses

Figure 22 Variation of permeability responding to in situ stresses 
Table Headers

Table 1 Three types of soils for assessment of plastic consolidation

Table 2 Input parameters for sensitivity analysis

Table 3 Oedometer testing results on undisturbed clay samples

Table 4 Interpretation results of PHT in borehole TB233

Table 5 Interpretation of results of six PHTs in Seattle clay 
Table 1. Three types of soils for assessment of plastic consolidation

\begin{tabular}{cccccc}
\hline & $\begin{array}{c}\text { Initial } \\
\text { Effective } \\
\text { Type } \\
\text { Stress, } \\
\sigma_{0}^{\prime} \\
(\mathrm{MPa})\end{array}$ & $\begin{array}{c}\text { Initial } \\
\text { Void } \\
\text { Ratio, }\end{array}$ & $\begin{array}{c}\text { Undrained } \\
\text { Shear } \\
\text { Strength, } \\
s_{u}(\mathrm{MPa})\end{array}$ & $\begin{array}{c}\text { Shear } \\
\text { Modulus, }\end{array}$ & $\begin{array}{c}\text { Elastic } \\
\text { Volumetric } \\
\text { Compression } \\
\text { Index, } \kappa\end{array}$ \\
\hline$\# 1$ & 1 & 1.5 & 0.577 & 23.1 & 0.06 \\
$\# 2$ & 2 & 1.0 & 1.154 & 46.2 & 0.03 \\
$\# 3$ & 3 & 0.6 & 1.732 & 69.3 & 0.015 \\
\hline
\end{tabular}


Table 2. Input parameters for sensitivity analysis

\begin{tabular}{cccccc|ccc}
\hline \multicolumn{3}{c|}{ Fixed Parameters } & \multicolumn{3}{c}{ Variables } \\
$\sigma_{0}^{\prime}$ & $S_{u}{ }^{*}$ & & & & & \multicolumn{3}{c}{} \\
$(\mathrm{MPa})$ & $(\mathrm{MPa})$ & $M$ & $e_{0}$ & $\kappa$ & $\lambda$ & $I_{r}$ & $(\mathrm{~cm} / \mathrm{s})$ & $R$ \\
\hline 2 & 0.25, & 1 & 1 & 0.0205 & 0.178 & 20,40, & $10^{-8}, 10^{-7}$, & $1.44,2.22$, \\
& 0.5, & & & & & 60,80 & $10^{-6}, 10^{-5}$, & 3.43 \\
& 1.154, & & & & & & $10^{-4}$ & \\
2 & & & & & & & \\
\hline
\end{tabular}


Table 3. Oedometer testing results on undisturbed clay samples

\begin{tabular}{|c|c|c|c|c|c|c|c|}
\hline $\begin{array}{l}\text { Borehole } \\
\text { ID }\end{array}$ & Geological Unit & $\begin{array}{l}\text { Recovered } \\
\text { Depth } \\
\text { (m) }\end{array}$ & $\begin{array}{l}\text { PI } \\
(\%)\end{array}$ & $\begin{array}{c}\text { Coefficient of } \\
\text { Volume Change } \\
c_{v} \\
\left(\mathrm{~cm}^{2} / \mathrm{s}\right)\end{array}$ & $\begin{array}{c}\text { Recompression } \\
\text { Index } \\
C_{r}\end{array}$ & $\begin{array}{c}\text { Virgin } \\
\text { Compression } \\
\text { Index } \\
C_{c}\end{array}$ & $\begin{array}{c}\text { Volumetric } \\
\text { Compression } \\
\text { Ratio } \\
\Lambda\end{array}$ \\
\hline 221 & $\begin{array}{l}\text { Glacio-lacustrine } \\
\text { Clay }\end{array}$ & 38 & 25 & $9.0 \times 10^{-3} \sim 4.5 \times 10^{-3}$ & 0.087 & 0.457 & 0.809 \\
\hline 238 & Lacustrine Clay & 38 & 17 & $8.0 \times 10^{-3} \sim 1.6 \times 10^{-2}$ & 0.052 & 0.272 & 0.810 \\
\hline 316 & $\begin{array}{l}\text { Glacio-lacustrine } \\
\text { Clay }\end{array}$ & 38 & 20 & $6.4 \times 10^{-3} \sim 7.9 \times 10^{-3}$ & 0.051 & 0.262 & 0.806 \\
\hline 221 & $\begin{array}{l}\text { Glacio-lacustrine } \\
\text { Clay }\end{array}$ & 42 & 20 & $8.0 \times 10^{-3} \sim 1.6 \times 10^{-2}$ & 0.068 & 0.353 & 0.808 \\
\hline $218 \mathrm{~A}$ & Lacustrine Clay & 44 & 51 & $5.2 \times 10^{-3} \sim 1.6 \times 10^{-2}$ & 0.165 & 0.836 & 0.802 \\
\hline 318 & $\begin{array}{l}\text { Glacio-lacustrine } \\
\text { Clay }\end{array}$ & 48 & 20 & $17.1 \times 10^{-3} \sim 3.2 \times 10^{-2}$ & 0.043 & 0.261 & 0.837 \\
\hline
\end{tabular}


Table 4. Interpretation results of PHT in borehole TB233

\begin{tabular}{cccccc}
\hline Test \# & $\varepsilon_{c}$ & $\Delta u_{\max } / s_{u}$ & $m_{h}^{e}\left(\mathrm{kPa}^{-1}\right)$ & $t_{17}(\mathrm{~s})$ & $k(\mathrm{~cm} / \mathrm{s})$ \\
\hline 1 & $0.78 \%$ & 1.88 & $4.25 \times 10^{-7}$ & 61 & $4.3 \times 10^{-9}$ \\
2 & $4.19 \%$ & 2.81 & $4.25 \times 10^{-7}$ & 59 & $1.25 \times 10^{-8}$ \\
\hline
\end{tabular}


Table 5. Interpretation of results of six PHTs in Seattle clay

\begin{tabular}{cccccccccc}
\hline $\begin{array}{c}\text { Borehole } \\
\text { No. }\end{array}$ & $\begin{array}{c}\text { Depth } \\
(\mathrm{m})\end{array}$ & $\begin{array}{c}P I \\
(\%)\end{array}$ & $\begin{array}{c}w_{c} \\
(\%)\end{array}$ & $\begin{array}{c}S_{u} \\
(\mathrm{kPa})\end{array}$ & $\begin{array}{c}G \\
(\mathrm{kPa})\end{array}$ & $\begin{array}{c}\sigma_{v_{0}}^{\prime} \\
(\mathrm{kPa})\end{array}$ & $\begin{array}{c}\sigma_{h_{0}}^{\prime} \\
(\mathrm{kPa})\end{array}$ & $\begin{array}{c}m_{h}^{e} \\
\left(\mathrm{kPa}^{-1}\right)\end{array}$ & $\begin{array}{c}k_{h} \\
(\mathrm{~cm} / \mathrm{s})\end{array}$ \\
\hline TB216 & 41 & 27 & 21 & 692 & $6.6 \times 10^{5}$ & 405 & 1325 & $3.83 \times 10^{-7}$ & $8.5 \times 10^{-9}$ \\
TB221 & 40 & 24 & 28 & 759 & $3.6 \times 10^{5}$ & 401 & 1149 & $7.09 \times 10^{-7}$ & $2.1 \times 10^{-9}$ \\
TB233 & 44 & 16 & 18 & 1410 & $6.0 \times 10^{5}$ & 443 & 1917 & $4.25 \times 10^{-7}$ & $4.8 \times 10^{-10}$ \\
TB321 & 44 & 31 & 25 & 180 & $1.6 \times 10^{4}$ & 436 & 557 & $1.63 \times 10^{-5}$ & $6.2 \times 10^{-8}$ \\
TB318 & 28 & 36 & 29 & 417 & $8.2 \times 10^{4}$ & 282 & 615 & $3.09 \times 10^{-6}$ & $5.0 \times 10^{-9}$ \\
TB318 & 38 & 26 & 28 & 673 & $9.8 \times 10^{4}$ & 378 & 1062 & $2.58 \times 10^{-6}$ & $2.5 \times 10^{-9}$ \\
\hline
\end{tabular}




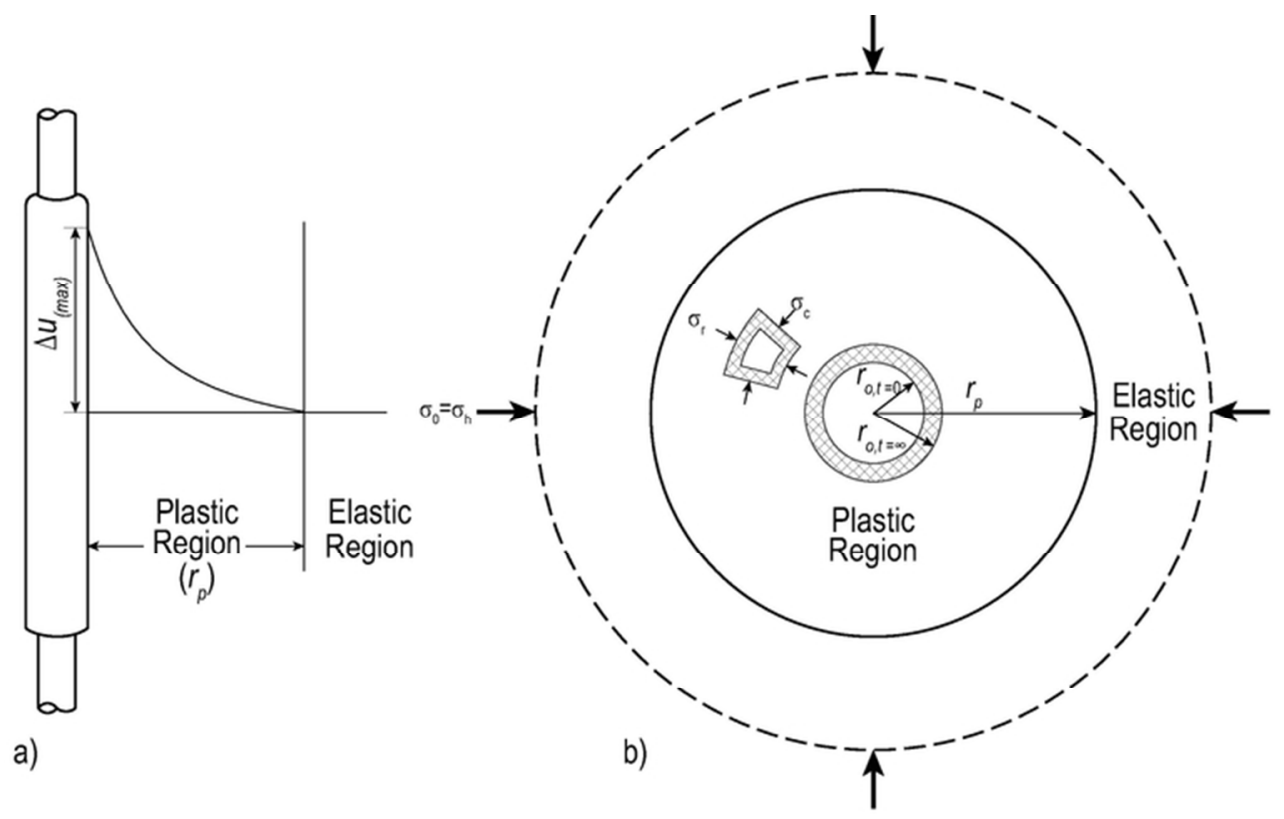

Figure 1 . Soil states in the cavity annulus before and after consolidation with fixed boundary loadings $65 \times 40 \mathrm{~mm}(300 \times 300 \mathrm{DPI})$ 


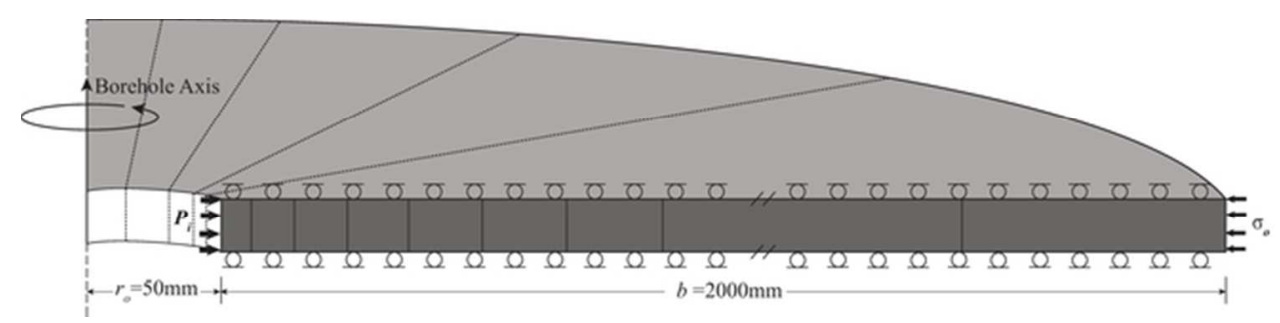

Figure 2. Geometry of the numerical model for PHT analysis

$57 \times 13 \mathrm{~mm}(300 \times 300$ DPI $)$ 


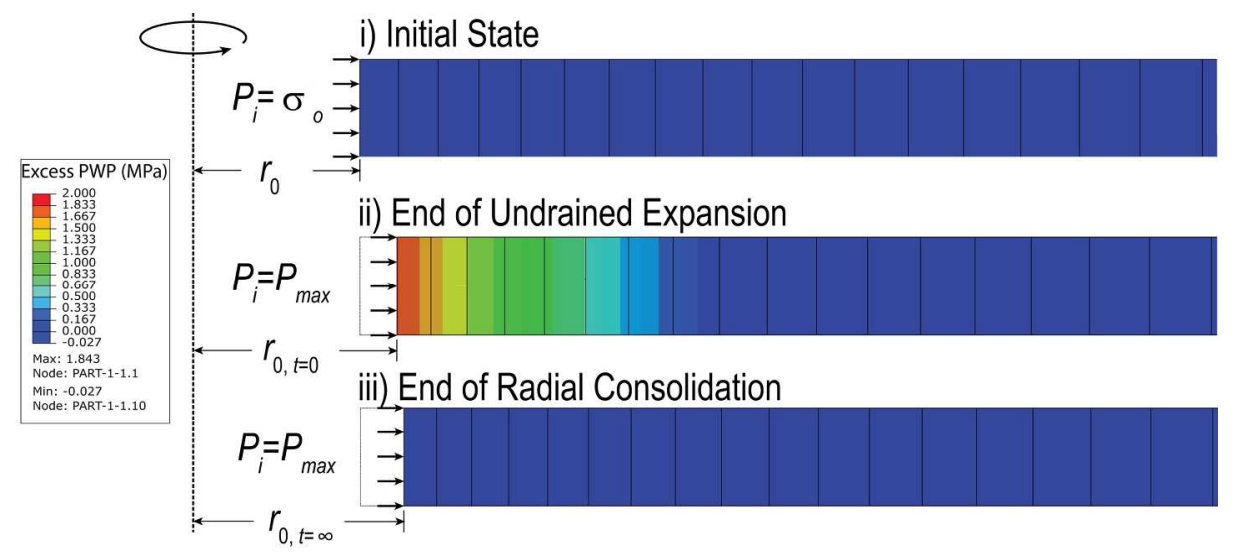

Figure 3. Calculated excess pore-water pressures and deformations $201 \times 84 \mathrm{~mm}(300 \times 300 \mathrm{DPI})$ 


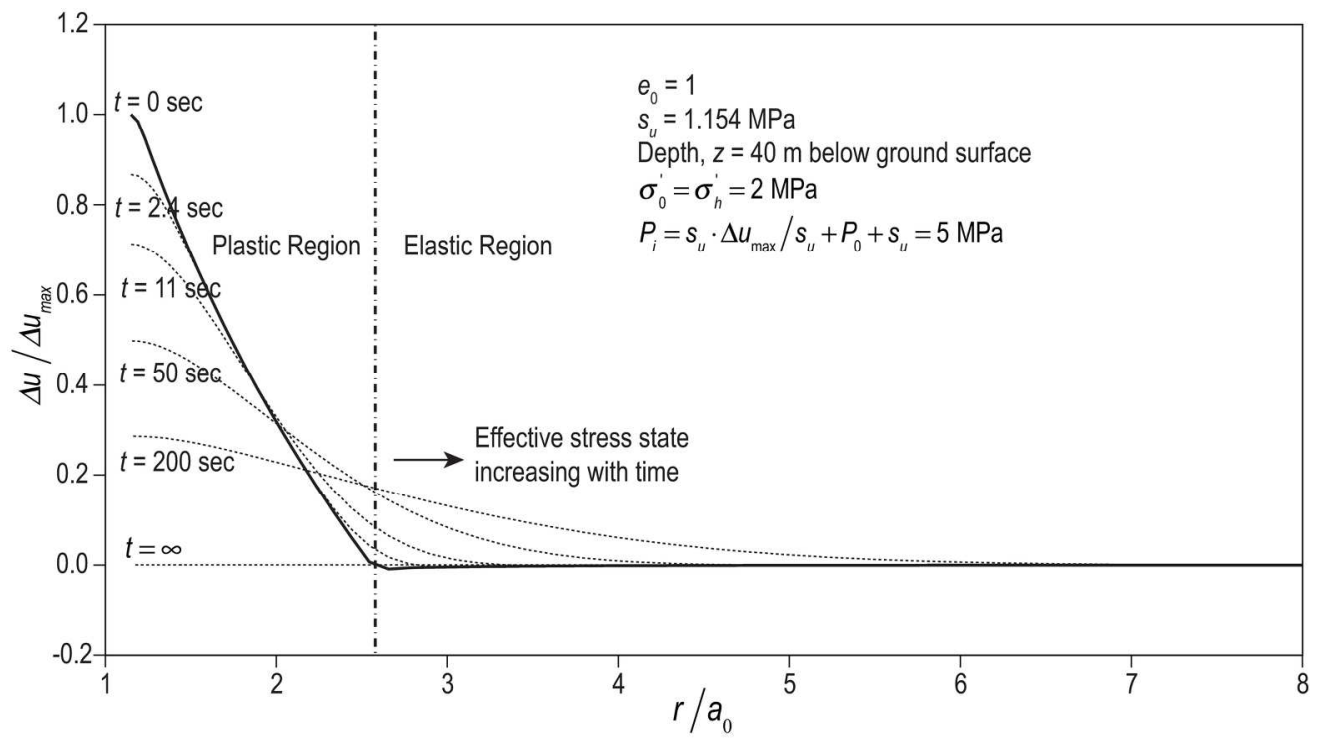

Figure 4. Variation of excess pore-water pressure in the soil annulus radius during $\mathrm{PHT}\left(\mathrm{I}_{\mathrm{r}}=\mathrm{G} / \mathrm{S}_{\mathrm{u}}=20, \mathrm{k}=10^{-7}\right.$ $\mathrm{cm} / \mathrm{s}$, and $\Delta \mathrm{u}_{\max } / \mathrm{S}_{\mathrm{u}}=1.6$ ) (modified from Randolph and Wroth 1979)

$190 \times 106 \mathrm{~mm}(300 \times 300 \mathrm{DPI})$ 


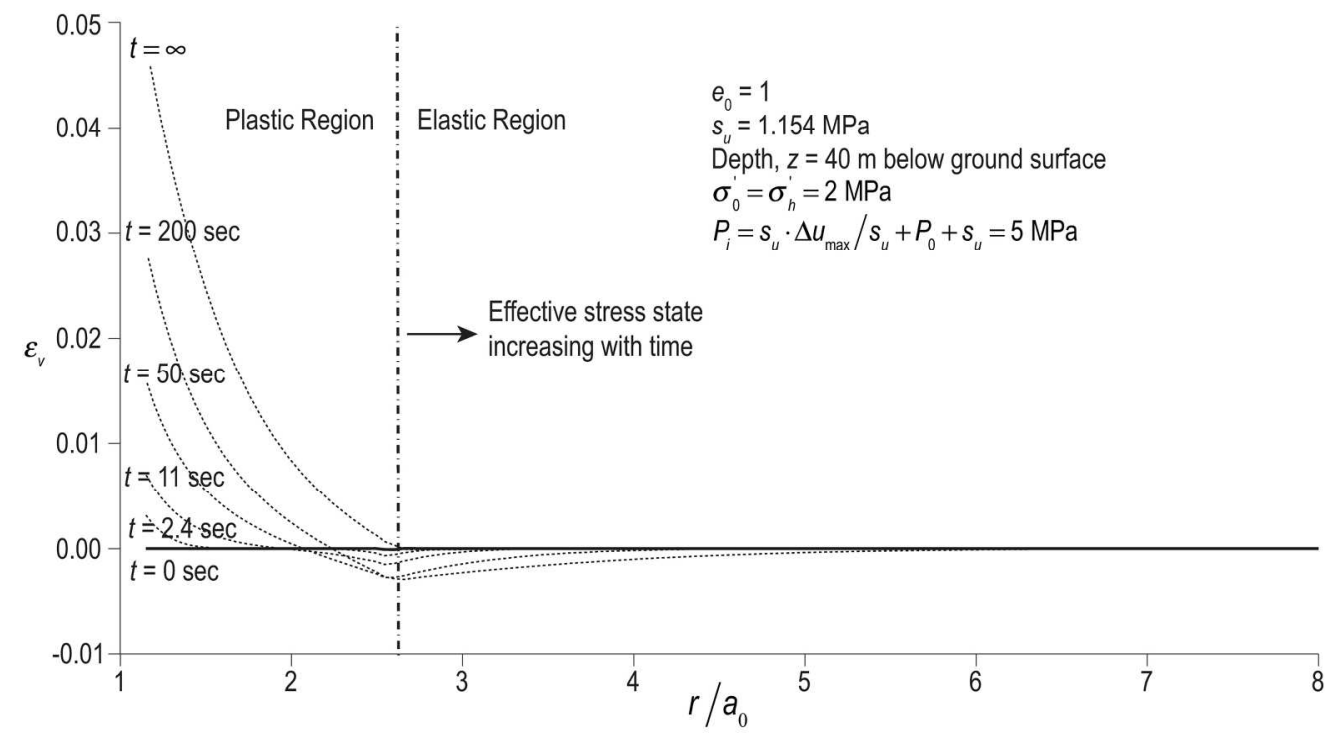

Figure 5. Typical variation of volumetric strain in the soil annulus radius during $\mathrm{PHT}\left(\mathrm{I}_{\mathrm{r}}=20, \mathrm{k}=10^{-7} \mathrm{~cm} / \mathrm{s}\right.$, and $\Delta \mathrm{u}_{\max } / \mathrm{S}_{\mathrm{u}}=1.6$ ). (modified from Randolph and Wroth 1979)

$188 \times 104 \mathrm{~mm}(300 \times 300 \mathrm{DPI})$ 


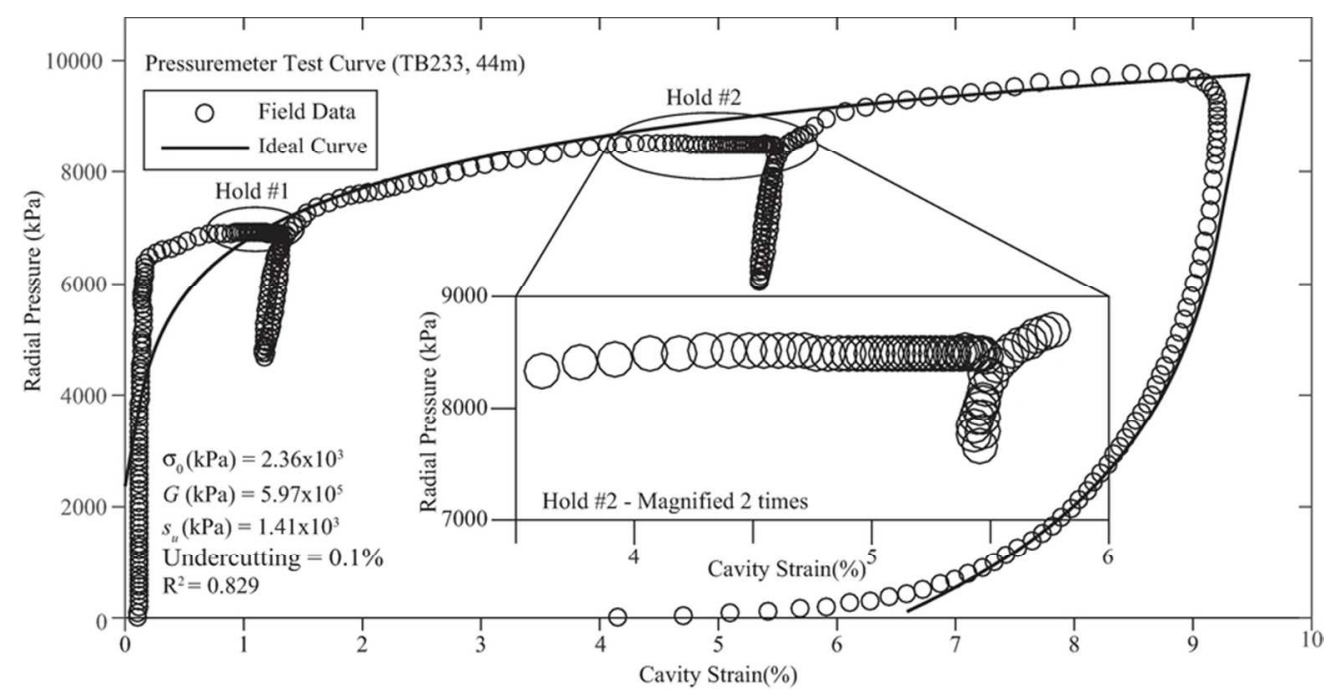

Figure 6. Fitting the pressuremeter testing data with the model curve (TB233, $44.3 \mathrm{~m}$ ) $81 \times 42 \mathrm{~mm}(300 \times 300$ DPI $)$ 


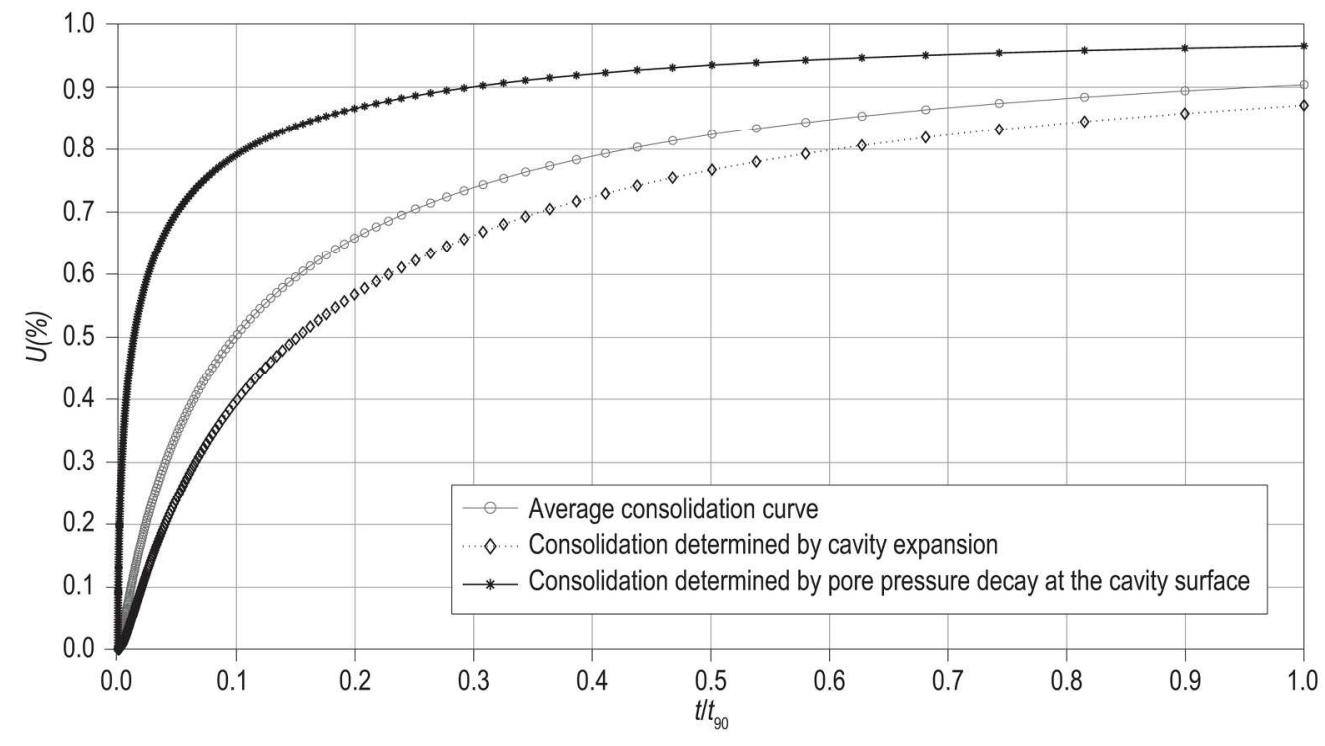

Figure 7. Representation of consolidation by excess pore-water pressure decay and radial displacement compared to the true average consolidation curve $\left(\mathrm{I}_{\mathrm{r}}=20, \mathrm{k}=10^{-7} \mathrm{~cm} / \mathrm{s}\right.$, and $\left.\Delta \mathrm{u}_{\max } / \mathrm{S}_{\mathrm{u}}=1.6\right)$

$192 \times 108 \mathrm{~mm}(300 \times 300 \mathrm{DPI})$ 


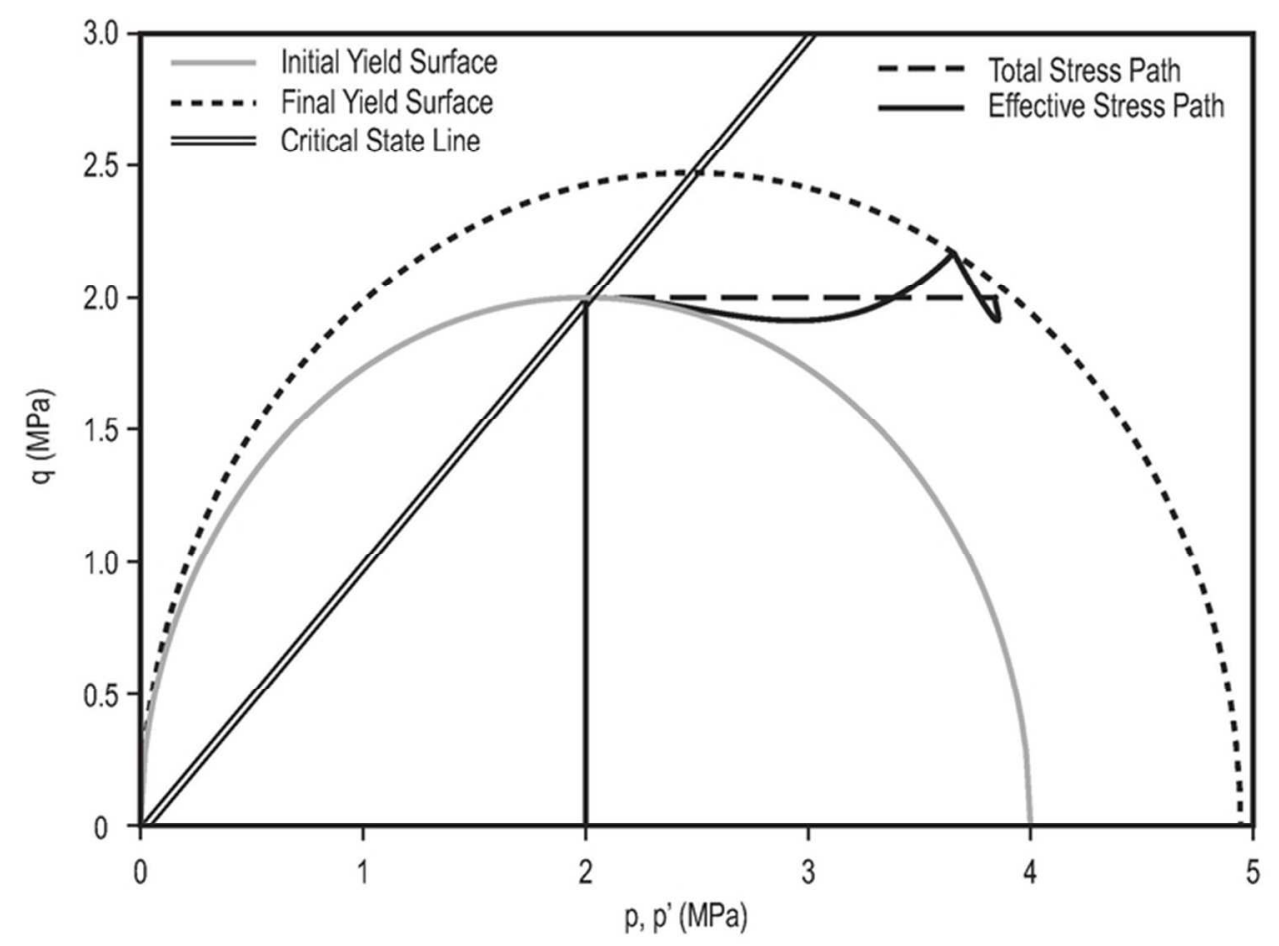

Figure 8. Effective and total stress paths during undrained expansion and consolidation $64 \times 46 \mathrm{~mm}(300 \times 300 \mathrm{DPI})$ 


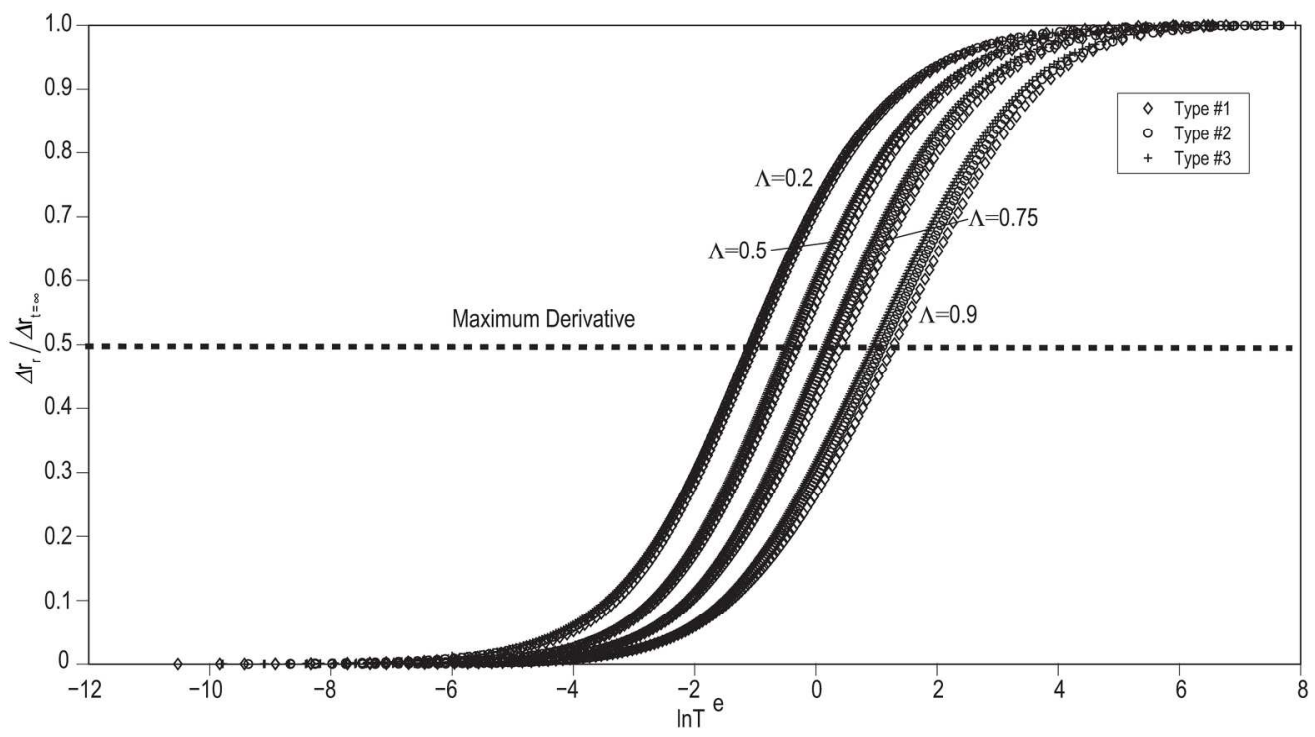

Figure 9. Variation of the normalized radial displacement during consolidation with the logarithm of time $\left(\Delta \mathrm{u}_{\max } / \mathrm{S}_{\mathrm{u}}=1.6\right.$ or $\left.R=4.95\right)$

$186 \times 104 \mathrm{~mm}(300 \times 300 \mathrm{DPI})$ 


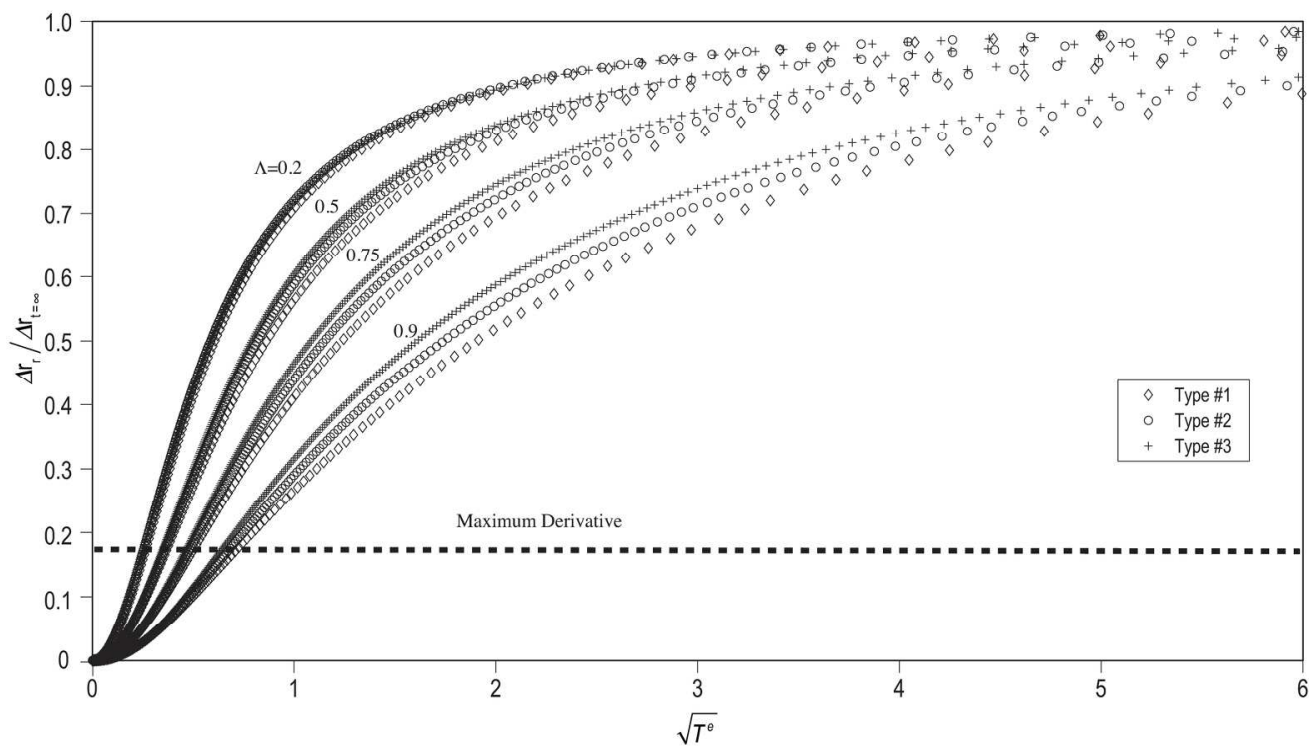

Figure 10. Variation of the normalized radial displacement during consolidation with the square root of time $\left(\Delta \mathrm{u}_{\max } / \mathrm{S}_{\mathrm{u}}=1.6\right.$ or $\left.R=4.95\right)$

$189 \times 107 \mathrm{~mm}$ ( $300 \times 300$ DPI) 


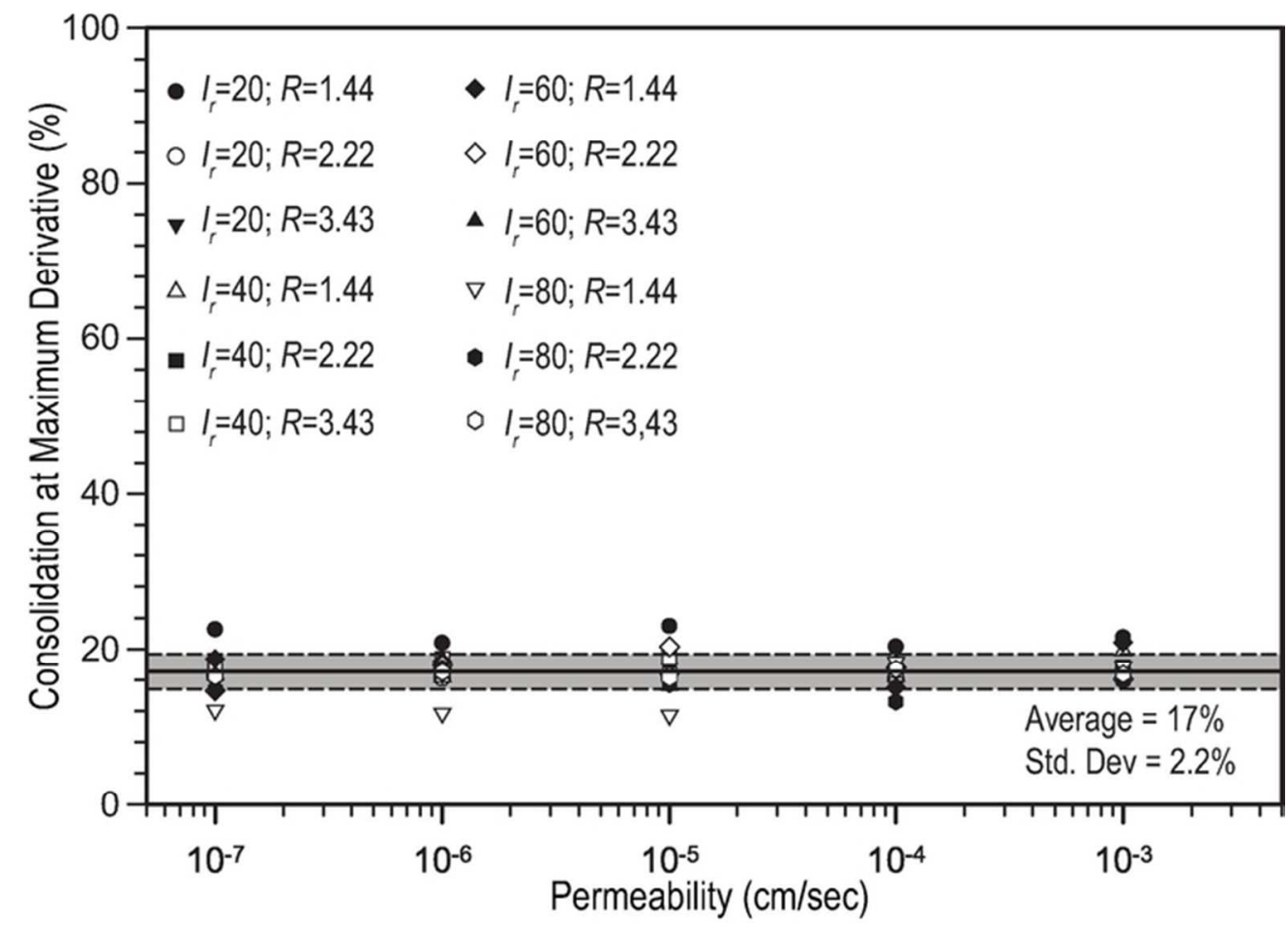

Figure 11. The varying values of $(d U)_{\max }$ in root time consolidation curves for different in situ parameters and induced excess pore-water pressure conditions from the numerical computation

$63 \times 45 \mathrm{~mm}(300 \times 300 \mathrm{DPI})$ 


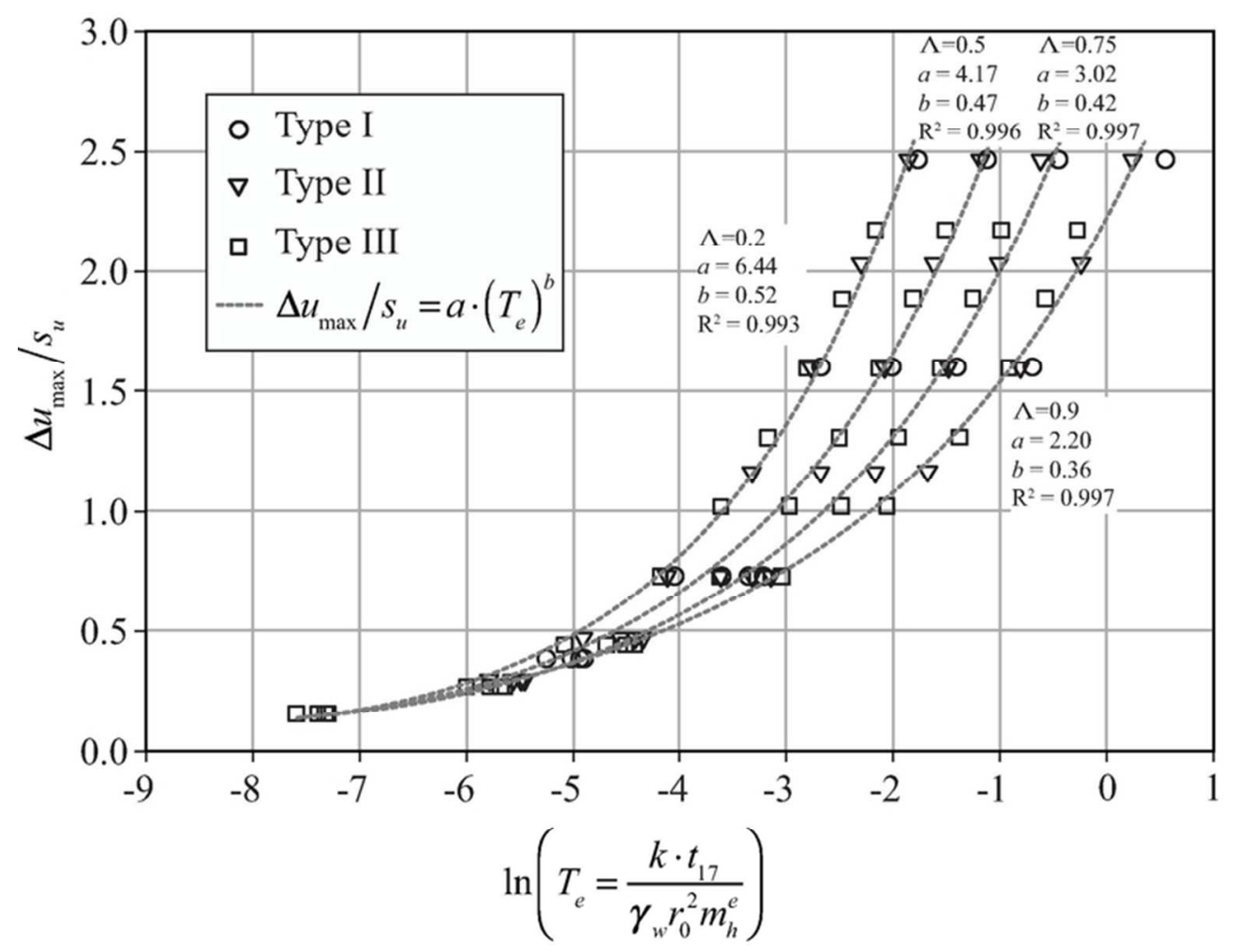

Figure 12. The non-dimensional time factor curve for $17 \%$ consolidation during a PHT $68 \times 52 \mathrm{~mm}(300 \times 300 \mathrm{DPI})$ 


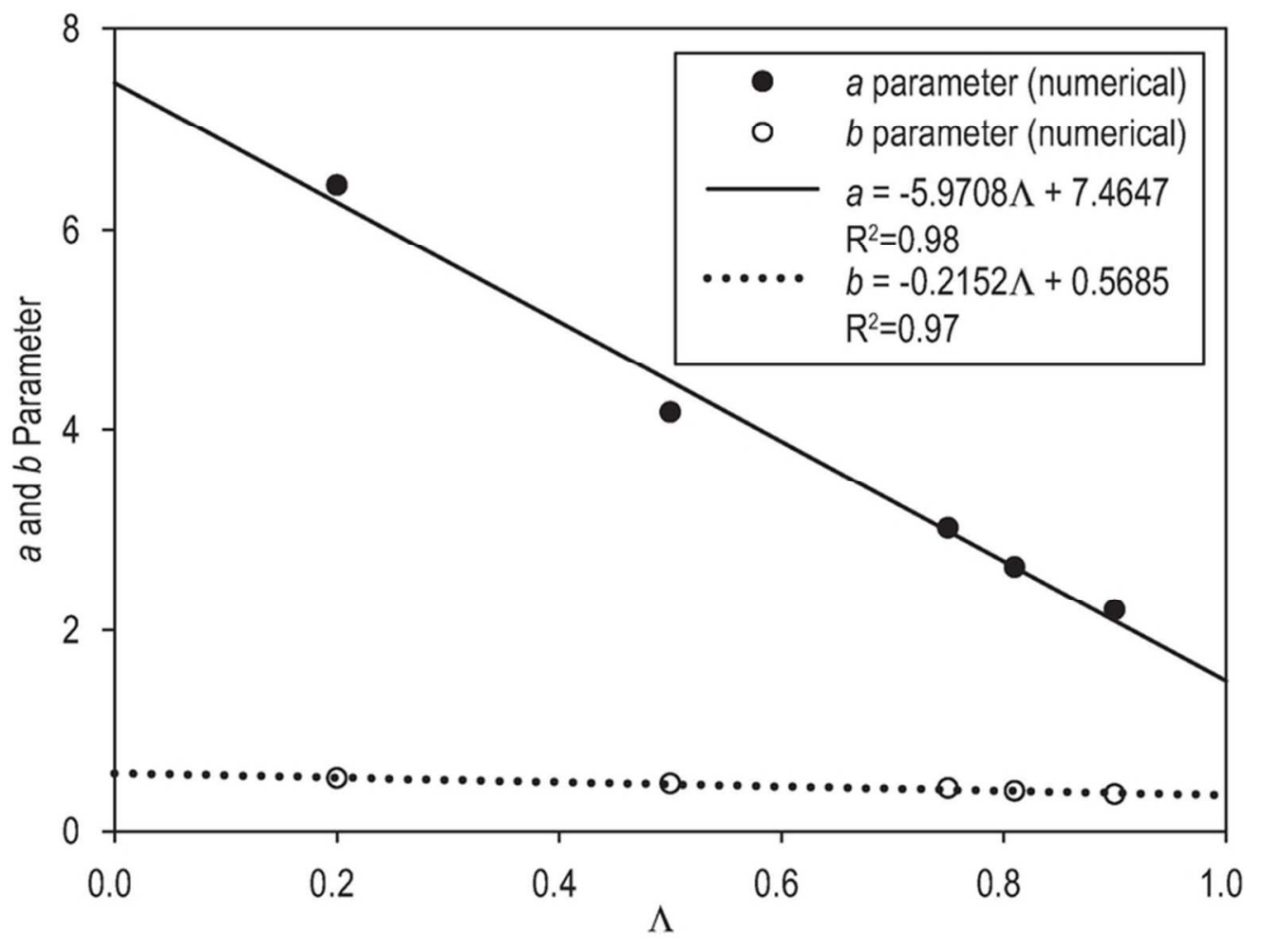

Figure 13. $a$ and $b$ parameters based on numerical results for varying $\wedge$ $68 \times 51 \mathrm{~mm}(300 \times 300 \mathrm{DPI})$ 


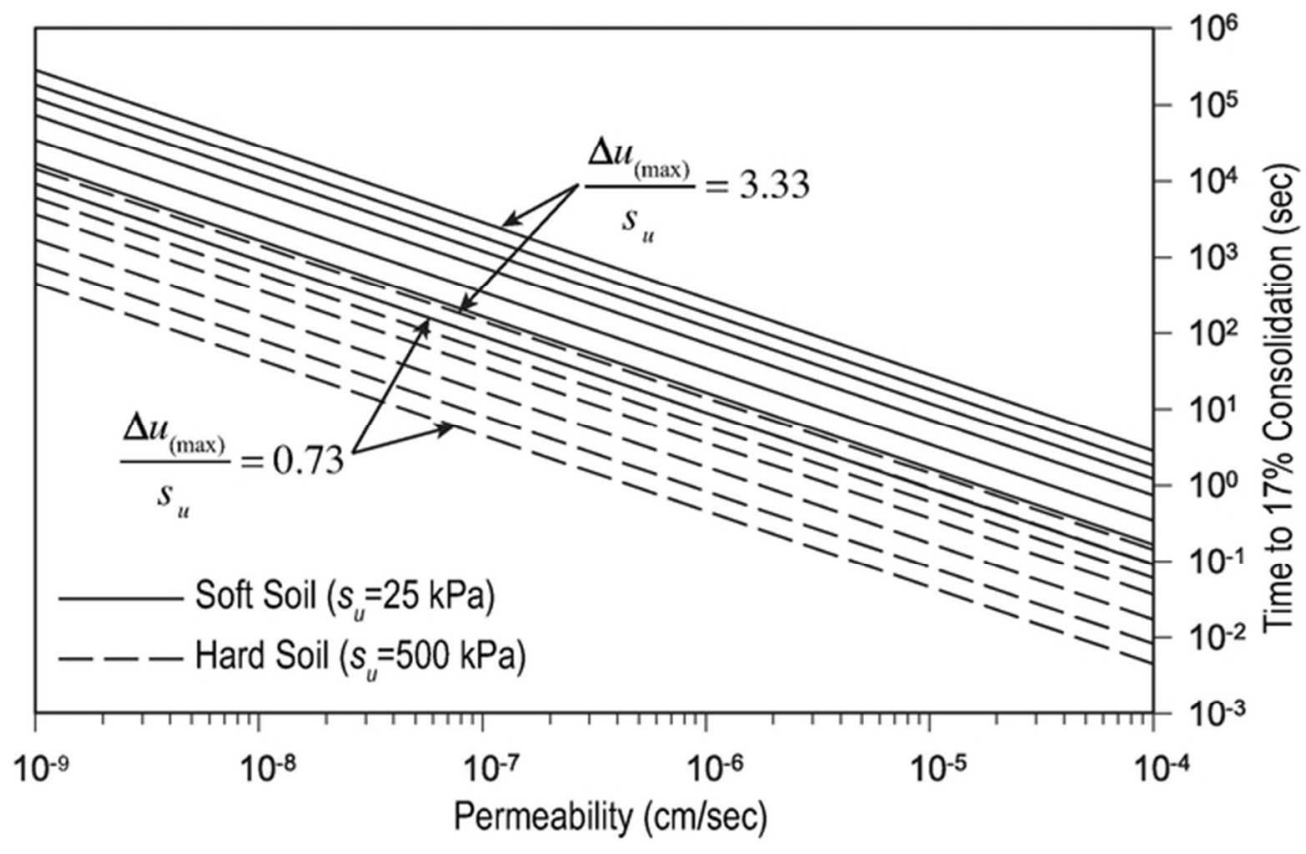

Figure 14. Time to reach $17 \%$ consolidation for PHT in soils of different stiffness $(\Lambda=0.75)$ $58 \times 37 \mathrm{~mm}(300 \times 300 \mathrm{DPI})$ 


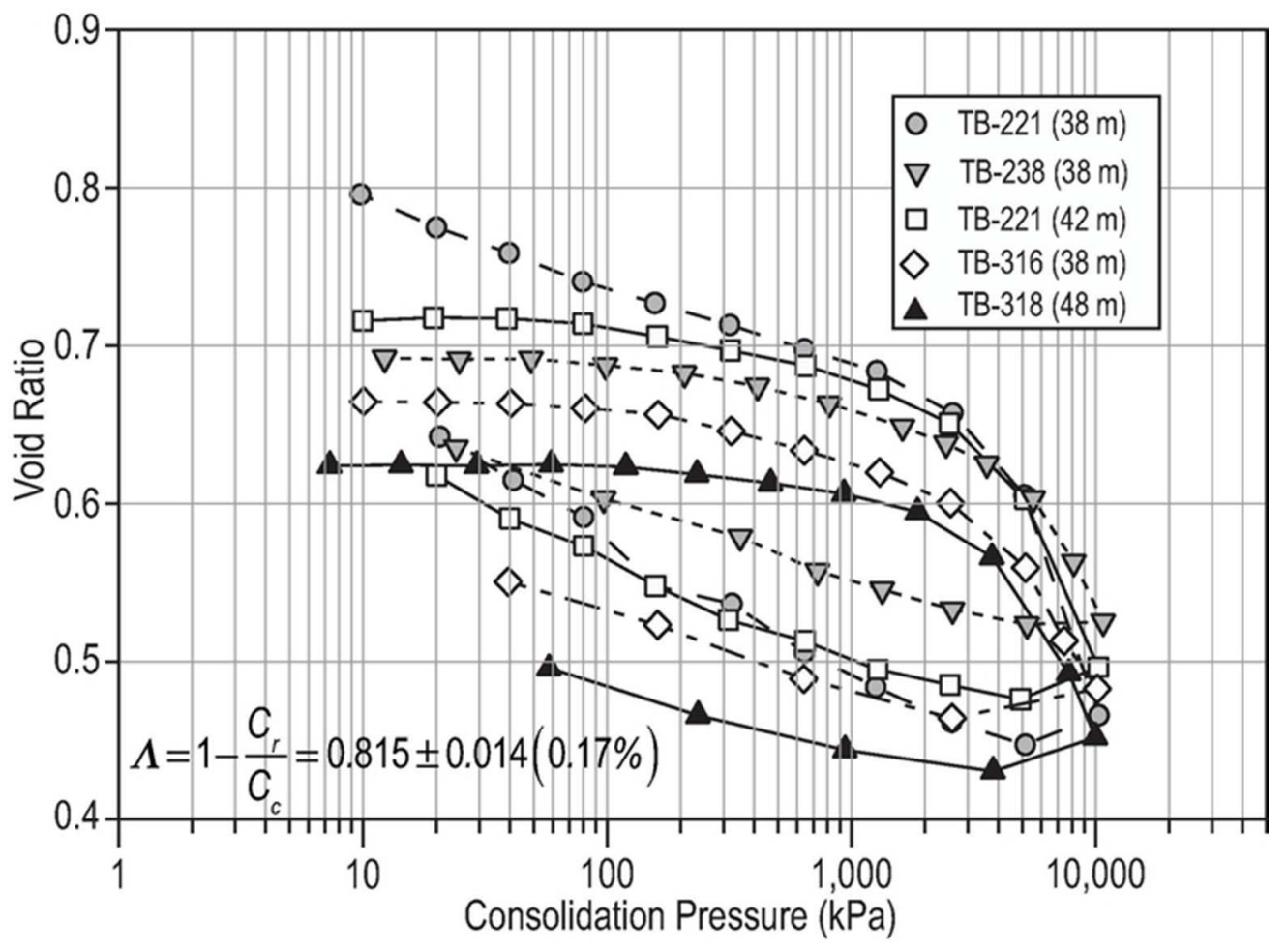

Figure 15. Settlement of clay samples at increasing consolidation pressure $62 \times 46 \mathrm{~mm}(300 \times 300 \mathrm{DPI})$ 


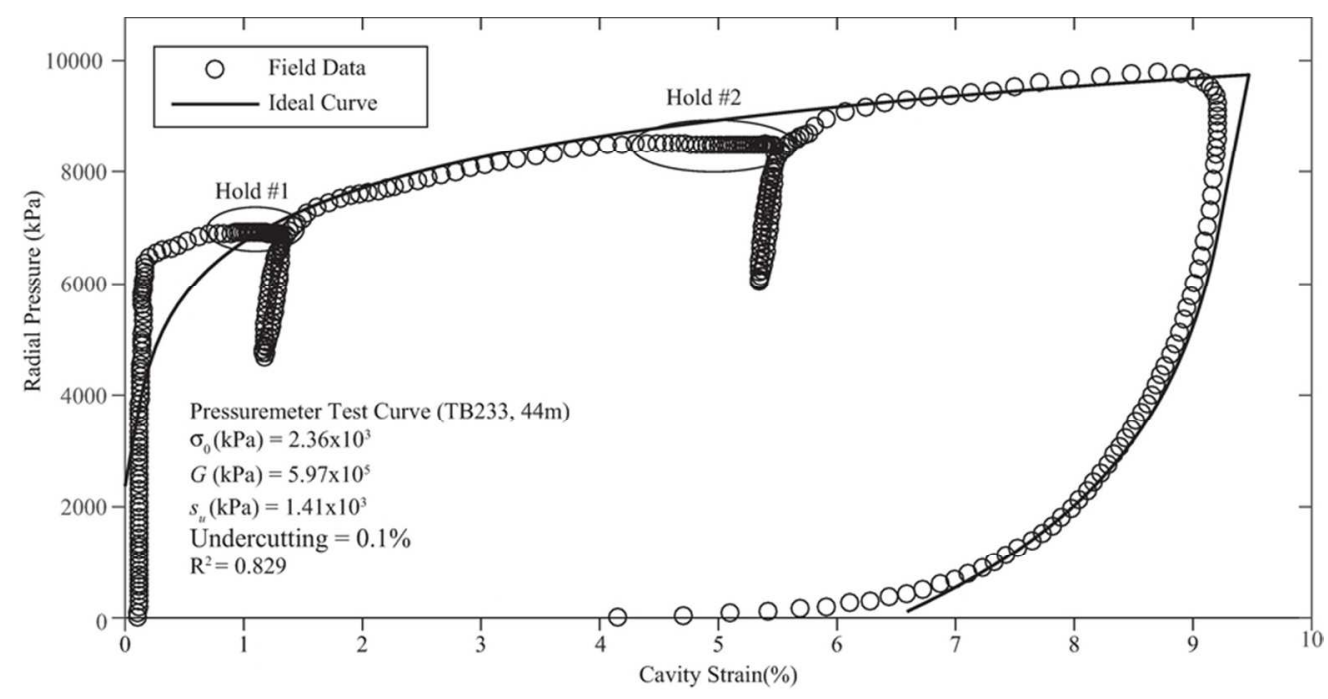

Figure 16. Fitting the pressuremeter testing data with the model curve (TB233, $44.3 \mathrm{~m}$ ) $81 \times 42 \mathrm{~mm}(300 \times 300$ DPI $)$ 


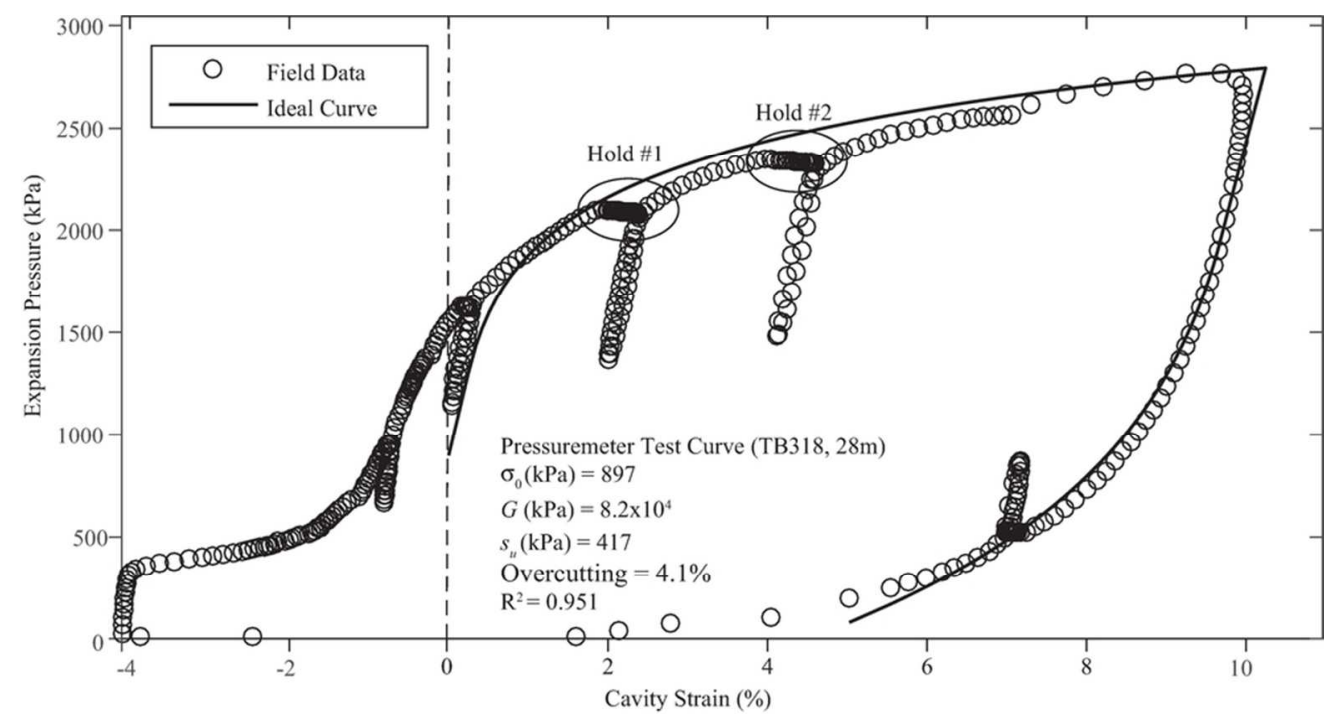

Figure 17. Fitting the pressuremeter testing data with the model curve (TB318, $28 \mathrm{~m}$ ) $83 \times 44 \mathrm{~mm}(300 \times 300$ DPI $)$ 


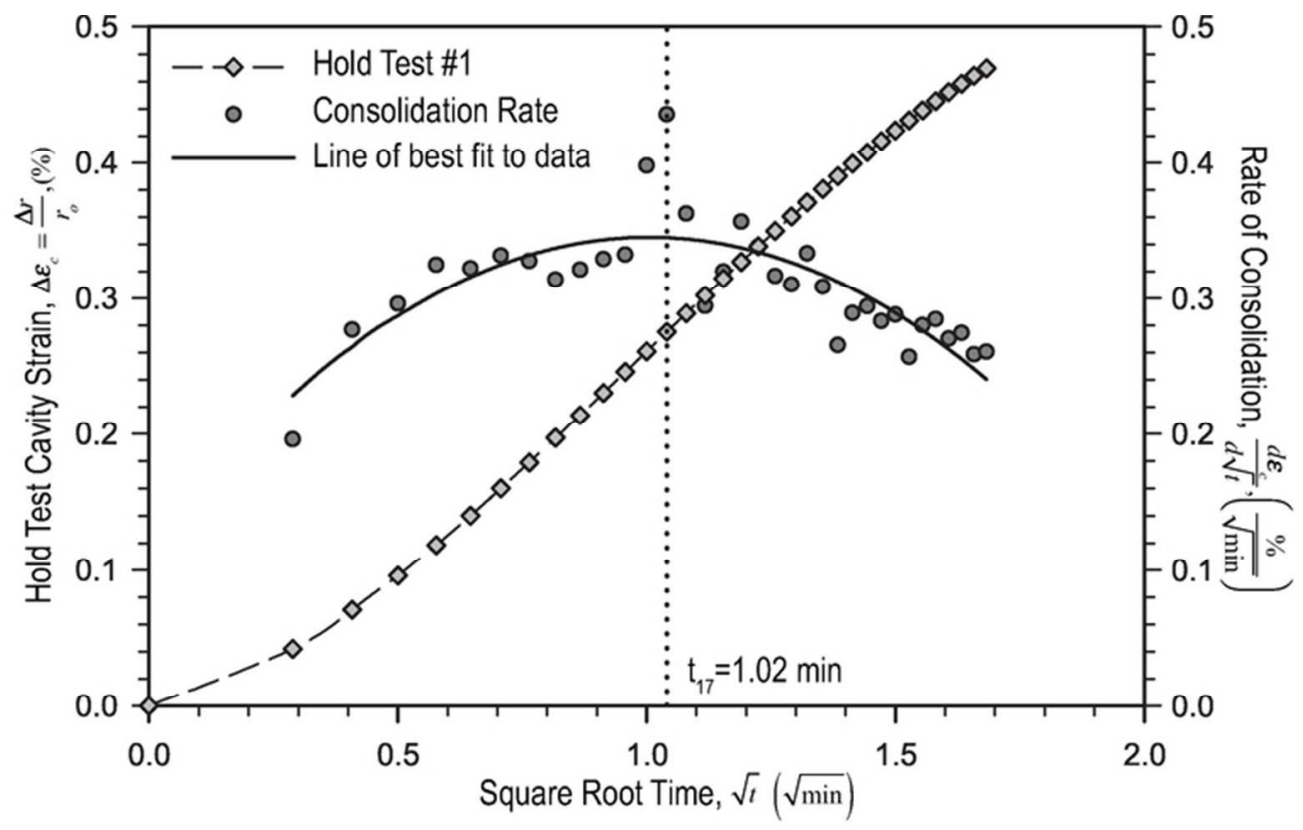

Figure 18. First hold test at $44.3 \mathrm{~m}$ for borehole TB233

$64 \times 40 \mathrm{~mm}(300 \times 300$ DPI $)$ 


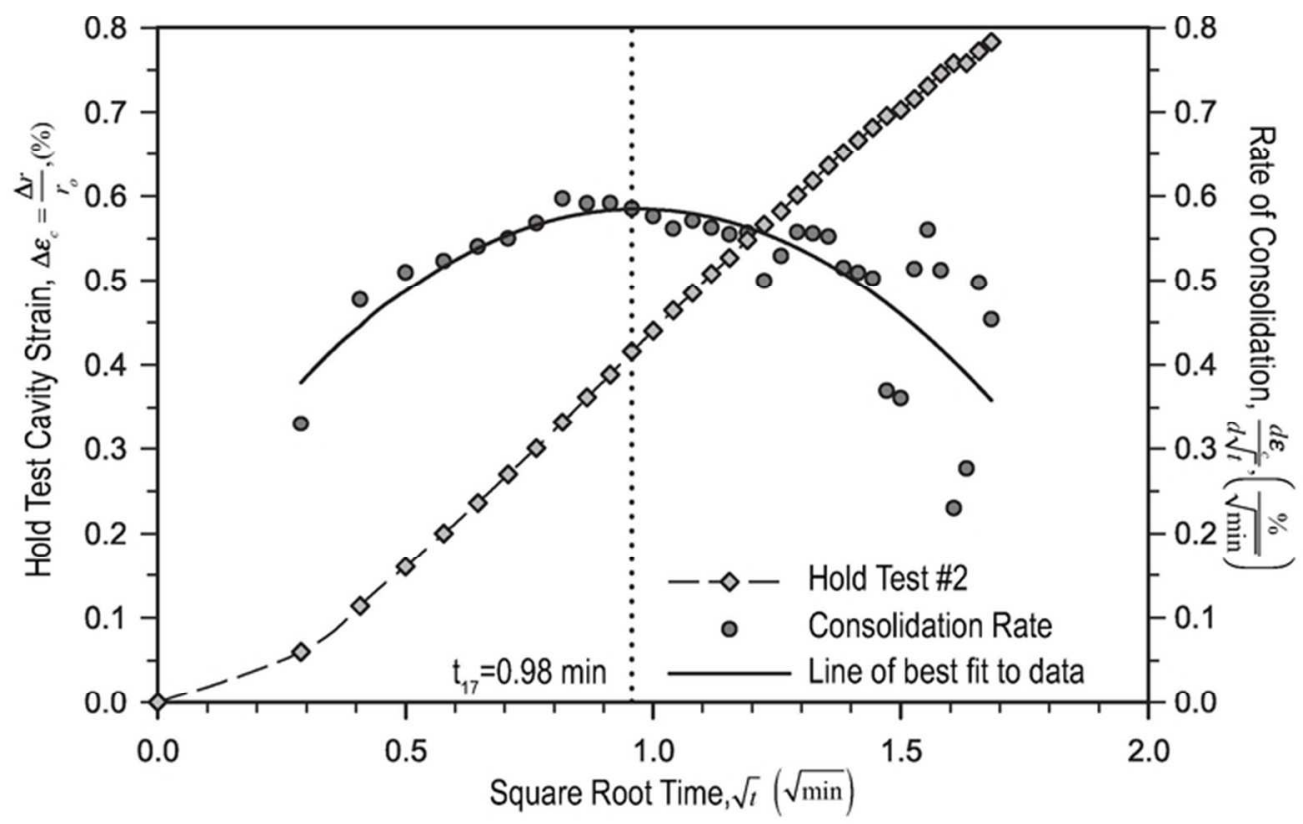

Figure 19. Second hold test at $44.3 \mathrm{~m}$ for borehole TB233

$64 \times 40 \mathrm{~mm}(300 \times 300 \mathrm{DPI})$ 


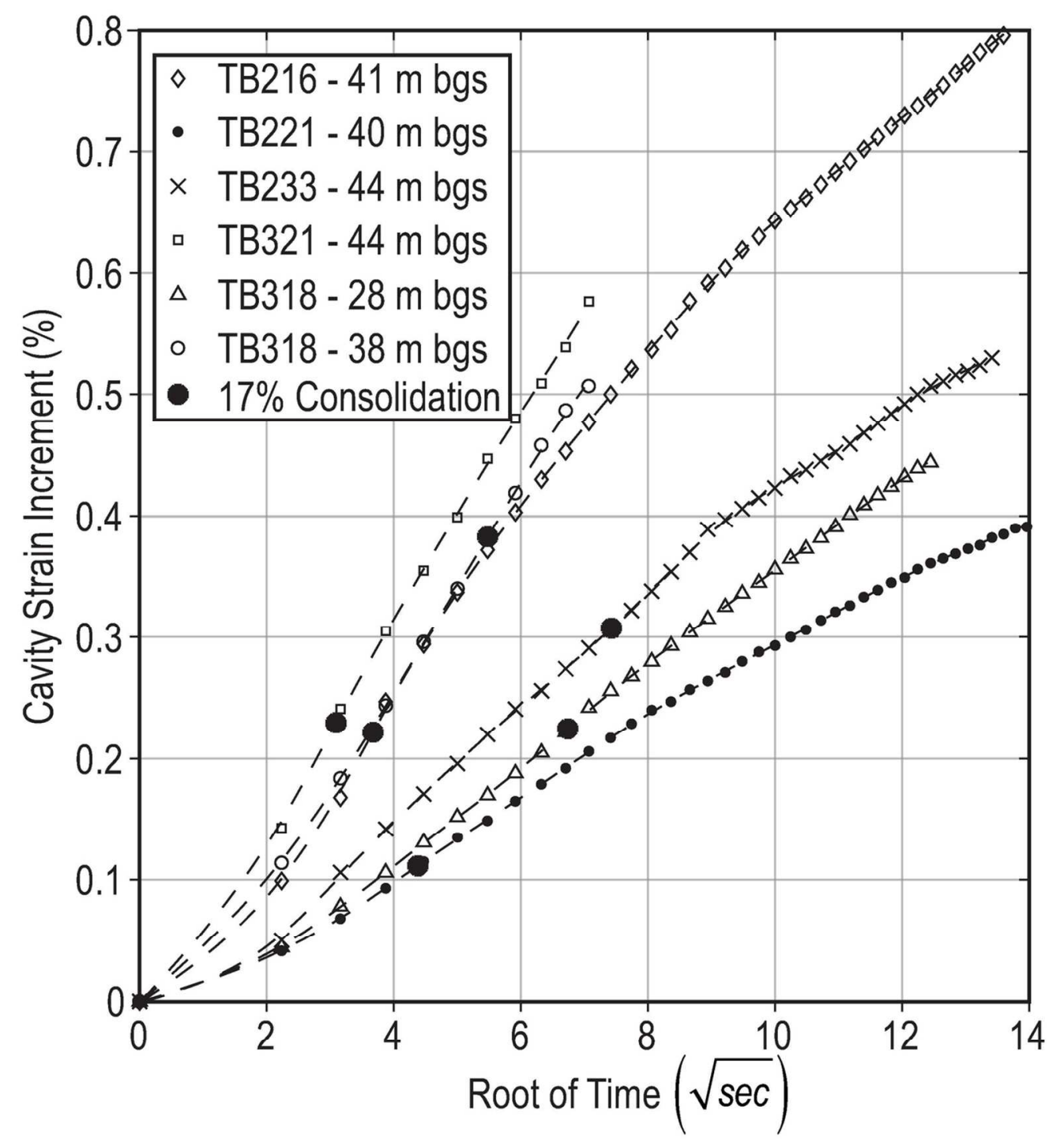

Figure 20. Root time curve of cavity strain variation during pressure hold tests in Seattle clay deposits; the point of $17 \%$ consolidation in each test is marked by a star symbol.

$114 \times 126 \mathrm{~mm}(300 \times 300 \mathrm{DPI})$ 


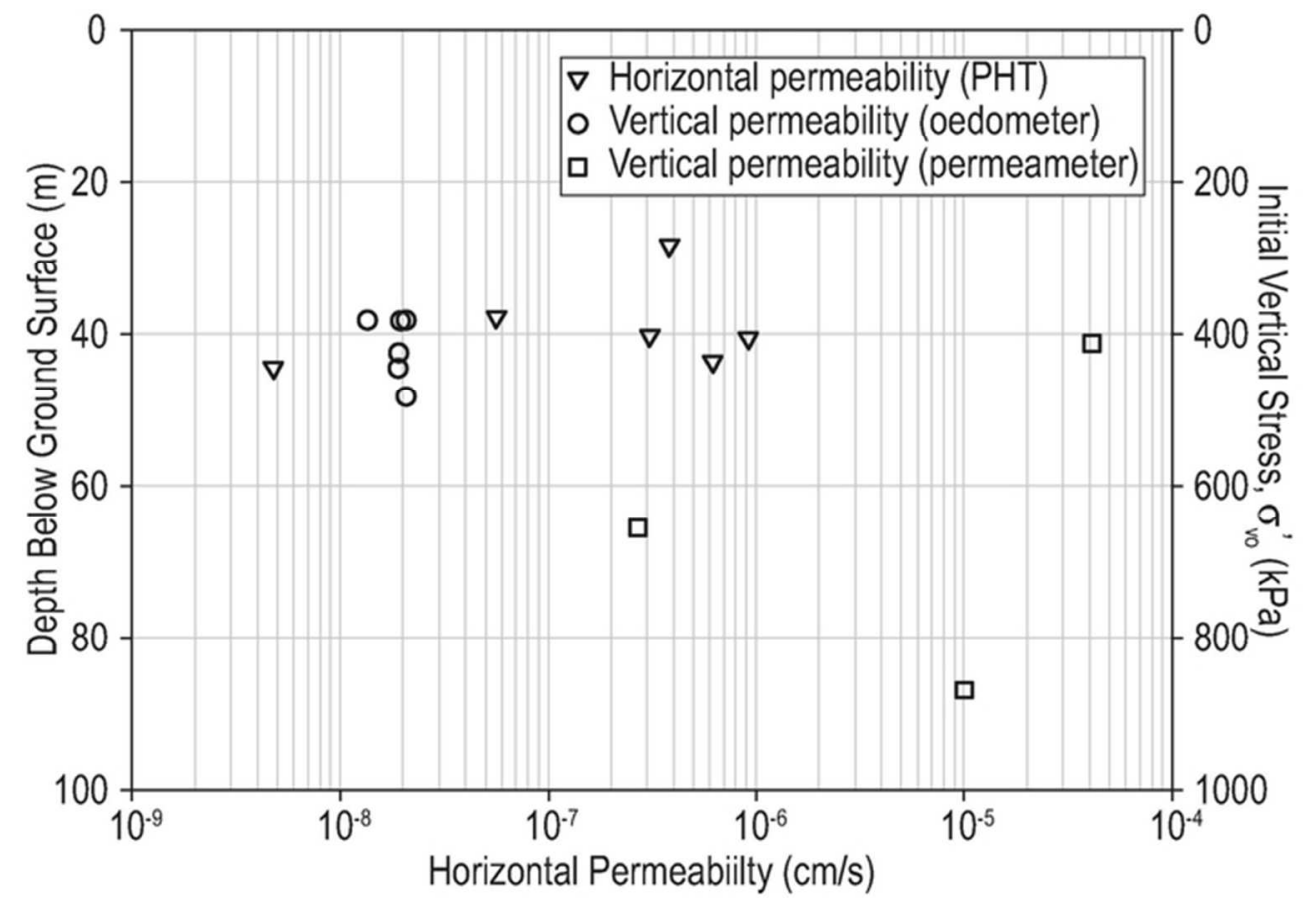

Figure 21. Permeability measured by PHT and laboratory testing versus effective vertical stresses $61 \times 41 \mathrm{~mm}(300 \times 300 \mathrm{DPI})$ 


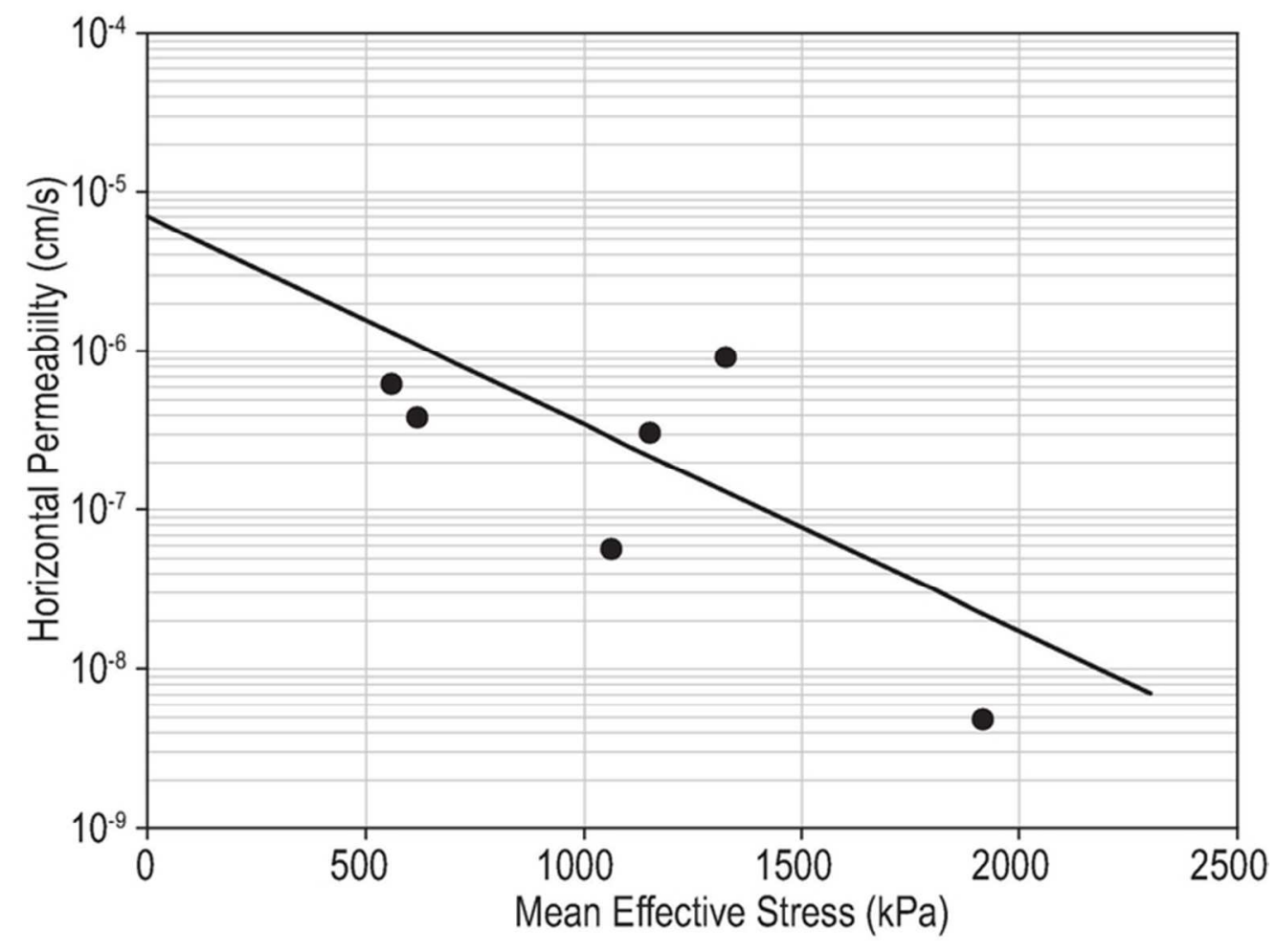

Figure 22. Variation of permeability responding to in situ stresses $62 \times 47 \mathrm{~mm}(300 \times 300 \mathrm{DPI})$ 